\title{
CORPORATISMO: EL ESTADO DE LA CUESTION
}

\section{Manuel Pérez Yruela y Salvador Giner}

\section{Introducción}

Con frecuencia los cambios sociales obligan a reconsiderar nuestros modelos y teorías sobre la sociedad, al tiempo que, con no menos frecuencia, desvelan los errores que cometemos al tratar de aprehender el sentido y la dirección del propio cambio. Por ello es fácil comprender el casi permanente estado de crisis de las ciencias sociales.

En los últimos decenios asistimos a una manifestación más de esta situación, a través de las diversas propuestas de redefinición de las características esenciales de las sociedades capitalistas avanzadas '. Estas sociedades, en su evolución, se han ido apartando cada vez más del modelo liberal-democrático, basado en la utopía liberal, que solía, y aún suele, emplearse para describirlas. Al mismo tiempo, tales sociedades no han cambiado ni sufrido crisis totalmente compatibles con y previsibles por la crítica que más sólidamente ha desmenuzado hasta ahora sus contradicciones: el marxismo. Parece, pues, necesario intentar reconstruir nuevos modelos de análisis y revisar la concepción del cambio que tenemos de ellas. Tarea ésta nada facil, pero sobre la que

${ }^{t}$ Para una revisión de estas definiciones y un análisis de sus orígenes en la sociología, puede verse S. Giner y M. Pérez Yruela (1979), pp. 9.20 y 27-51. 
existe mayor acuerdo entre economistas, politólogos y sociólogos del que podría sugerir la intensidad de sus disputas.

Los intentos que en este sentido se han venido produciendo han tenido alcances distintos. En unos casos se han reducido a etiquetar estas sociedades con adjetivos más o menos acertados (o esotéricos, como en el caso de la «sociedad tecnotrónica»). En otros se ha aislado una característica importante para reconstruir en torno a ella un modelo, considerando aquélla como un elemento vertebrado. Tal es el caso de las teorías sobre la sociedad «industrial» y «postindustrial», por una parte, o del «capitalismo monopolista», por otra.

Otros intentos menos globalizantes han consistido en revisar y criticar hipótesis específicas sobre su funcionamiento. Desde la ciencia política se ha hecho una revisión casi permanente de la estructura y funcionamiento del sistema de representación de intereses en estas democracias. Así, se ha dado por supuesto un paso de la estructura de intereses atomizados de la sociedad liberal a otra de intereses organizados y mediatizados ${ }^{2}$. Desde la economía se ha insistido en las restricciones a la noción de competencia perfecta, en las tendencias monopolísticas y en la función cada vez más activa del Estado en la regulación del sistema económico ${ }^{3}$. Desde la sociología se han puesto de manifiesto las limitaciones del «análisis de clase» para comprender la estructura social. El proceso de división del trabajo, el crecimiento de los salarios y del nivel de consumo, la interposición y mediación de nuevos grupos sociales entre capitalistas y trabajadores, el crecimiento del sindicalismo reformista y la aparición de nuevos grupos y movimientos conflictivos, han hecho mucho más complejo el entramado social y falsado en cierta medida las predicciones teóricas del análisis clasista tradicional ${ }^{4}$. Todas estas cuestiones, que no agotan los problemas de las sociedades capitalistas avanzadas, suponen modificaciones importantes del modelo clásico de democracia liberal.

Pese a lo anterior, no puede decirse que las transformaciones que se han producido en estas sociedades hayan eliminado completamente sus características estructurales. El sistema parlamentario, la economía de mercado, los modos de dominación, la desigualdad social y el conflicto continúan presentes, aun con todas las limitaciones apuntadas. Por ello, el objetivo de estos intentos de reinterpretación no debe ser alumbrar modelos de sociedad absolutamente nuevos, porque no es éste el caso, sino identificar qué variables han aparecido que alteran más o menos profundamente la concepción que se ha venido teniendo de ellas. $Y$ aunque ya han sido muchas las aportaciones en esta dirección, el avance ha sido menor cuando se trata de integrar variables que afectan a aspectos parciales en niveles más generales de interpretación.

${ }^{2}$ M. Maraffi (1981) ha hecho una revisión muy interesante de estas transformaciones, situando al corporatismo como una variedad del pluralismo.

${ }^{3}$ Dentro de la bibliografía existente sobre este tema, puede verse J. Robinson (1933).

4 Sobre estos problemas existen muchas aportaciones, como las de S. Mallet (1963), R. Darhendorf (1959) o D. Bell (1974). Un resumen de estos planteamientos puede verse en K. Kumar (1978). 
En definitiva, cuando se trata de encontrar una o unas pocas de variables a través de las que puedan explicarse los cambios acaecidos en diversos niveles de estas sociedades.

En este contexto puede situarse la tendencia creciente hoy a hablar de sociedades corporativas o neocorporativas o a considerar el aumento de la corporatización o corporativización como proceso en el que convergen total o parcialmente los cambios que han experimentado. Se trata de un nuevo intento de interpretación que ha encontrado amplia aceptación en áreas diferentes de las ciencias sociales. Pero a diferencia de otros, en este caso, la interpretación de algunos de los cambios sociales más recientes se hace por referencia a un modelo social —el corporativismo - que se había llegado a dar por periclitado.

El término corporativismo no es nuevo en las ciencias sociales. Su actual recuperación tiene sentido en la medida en que el corporativismo de finales del siglo $\mathrm{xIx}$ y comienzos del $\mathrm{xx}$ y las tendencias que en su dirección se observan en las sociedades capitalistas avanzadas tienen algunos rasgos comunes. No obstante, existen entre ellos diferencias sustantivas y, sobre todo, es radicalmente diferente la sociogénesis de ambas. Las similitudes permiten establecer un tronco común en el modelo, al tiempo que las diferencias ponen de manifiesto las diversas formas que puede adoptar bajo diferentes condiciones sociales, políticas y económicas. La rapidez con que se han extendido las referencias al análisis corporatista en la actualidad produce la impresión de que se está reviviendo una tradición teórica que muy bien pudiera convertirse pronto en hegemónica, si es que no lo es ya.

En este breve ensayo pretendemos dar cuenta del estado actual del debate sobre el corporatismo, así como de las limitaciones que, a nuestro juicio, tiene la orientación predominante que se está empleando. Orientación que, podemos anticipar, se reduce demasiado estrechamente a las manifestaciones que tiene en el área de la economía política. Lo que parece llamar más la atención de los investigadores es la formulación de la política económica en muchos países mediante acuerdos entre gobiernos, patronales y sindicatos. Esta es una muestra importante de las tendencias corporatistas, pero sería miope reducir el fenómeno a esta sola manifestación. Sostendremos, pues, que el corporatismo moderno es también un fenómeno más amplio cuyos efectos totales pueden alcanzar al conjunto de la sociedad y a sus formas actuales de reestructuración y conflicto. No obstante, no creemos que la posible corporatización de las sociedades avanzadas contemporáneas las cubra enteramente. Al contrario, se trata para nosotros de una dimensión, de una faceta solamente, de una realidad mucho más compleja, la mayor parte de la cual se escapa, sin duda, a lo que se pueda entender por corporatismo. 


\section{Origen del debate}

La perspectiva corporatista es una serpiente de verano que aparece y desaparece en los últimos cien años en diversas ramas de la filosofía y las ciencias sociales y en la práctica política. Primero apareció la «doctrina corporativa» sobre el Estado y la sociedad que pretendía recomponer normativamente, desde arriba, el orden social que desapareció con la revolución industrial y las primeras fases del capitalismo ${ }^{5}$.

Paralelamente, y en estrecha conexión con la anterior, se desarrolló la llamada «doctrina social católica». A través de las encíclicas pontificias, y en especial la Rerum Novarum de León XIII, se anatemizó el pensamiento marxista tras haberse hecho lo propio con el liberal, en todo lo que contenía de materialista y revolucionario. Sobre todo, oponiendo a la concepción de una sociedad escindida, injusta y permanentemente enfrentada a través de la lucha de clases, la de una sociedad integrada, armoniosa, en la que el ideal de justicia no se alcanzase por la victoria revolucionaria de una clase social que impondría su dictadura al resto de la sociedad, sino por la armonización de los intereses opuestos de las clases sociales, por la integración en el Estado de esos intereses a través de organizaciones patronales y de trabajadores, por la función mediadora del Estado en la solución de los conflictos en aras del «bien común» y por la nivelación de las desigualdades basada en la noción jerárquica de la «justicia distributiva» ${ }^{6}$.

Después fue la práctica política de estas ideas, con más o menos desviaciones de los planteamientos doctrinales. El primorriverismo en la España de los'veinte y después el franquismo, el salazarismo en Portugal, el conservadurismo gremialista austríaco, el fascismo italiano y las varias dictaduras latinoamericanas, son ejemplo de la pervivencia de manifestaciones más o menos puras de ese corporativismo católico y ultraconservador, que ha llegado prácticamente hasta nuestros días.

Tal tradición ha pervivido en determinadas ideologías, así como en la práctica política, y se ha localizado en países subdesarrollados o en vías de desarrollo del primer cinturón periférico de los países desarrollados. En ellos, mientras tanto, se iba afianzando un modelo completamente distinto: la democracia liberal, que ha convivido intermitentemente largos años con aquél, y al que incluso ha combatido.

En la evolución de las demacracias liberales se han producido cambios que las han alejado de los primeros modelos que de ellas se formularon y las han acercado al modelo corporativo. Fundamentalmente ha ido cambiando la sociedad basada en pequeñas unidades de producción en un mercado de competencia cuasi perfecta y en sujetos autónomos actuando individual y libre-

${ }^{5}$ Sobre estas doctrinas en Europa, cfr. M. H. Elbow (1966) y R. H. Bower (1974).

- Para un análisis de la doctrina social católica y sus relaciones con el corporativismo, cfr. J. Villain (1957). 
mente, amparados por un Estado meramente vigilante, rehacio a interferir en la esfera de la sociedad civil. Este modelo se ha ido sustituyendo progresivamente por un modelo de «sociedad organizada», porque en estas sociedades ha crecido visiblemente la diferenciación y la especialización que conllevan un aumento de la coordinación imperativa y de la organización si ha de mantenerse un grado mínimo de integración en el sistema. Y también porque la acción individual libre y descoordinada ha sido progresivamente sustituida por la acción social colectiva. Esta fórmula es, en muchos casos, más eficaz que aquélla para satisfacer intereses y alcanzar objetivos, no sólo colectivos sino, paradójicamente, individuales, para los free riders o beneficiarios francos de la acción colectiva que sin aportar nada se benefician de ella.

El avance de la «sociedad organizada" ha sido objeto de atención preferente en la sociología ${ }^{7}$. El énfasis ha sido mayor en el estudio de las características intraorganizativas en ámbitos diversos: la burocracia estatal, las organizaciones políticas (partidos, sindicatos, parlamentos), los servicios sociales, los ejércitos, los cuerpos de seguridad y las empresas. Relativamente han sido objeto de menor atención los efectos sociales de este nuevo fenómeno y, sobre todo, las características de las relaciones interorganizativas.

Dentro de la evolución anterior dos aspectos han adquirido una visibilidad especial: la articulación de intereses a través de organizaciones y las relaciones entre gobierno, sindicatos y patronales con objeto de acordar medidas de política económica. Estas relaciones tienen, además, algunos rasgos peculiares: cierto monopolio representativo de quienes participan en ellas; la fuerza de obligar que tienen los acuerdos para los miembros de las organizaciones que las suscriben; la institucionalización jurídica, en algunos casos, del órgano negociador; la intervención legitimadora del Estado al sancionar qué organizaciones pueden acceder al órgano negociador y su misma participación en ellas. Esta estructura recuerda algunas propuestas del corporativismo clásico, de manera que en este punto se entrevera aquella tradición con la evolución reciente de las democracias liberales. De forma espontánea han surgido en el seno de estas sociedades organizaciones de representación de intereses y se practican fórmulas para la integración y conciliación, que se asemejan al modelo corporativo, aunque tengan origen y alcance diferente.

Estas cuestiones no son las únicas, aunque sean las más visibles que dan cuenta de los cambios ocurridos en las democracias liberales desarrolladas. Hay otras, no menos importantes, que trataremos a continuación. Todas ellas han estimulado el debate sobre las tendencias corporatistas actuales.

' Cfr., por ejemplo, R. Presthus (1979); R. Collins (1975), pp. 285-346; M. García Pelayo (1977 b); K. Boulding (1953). 


\section{La sociogénesis del corporatismo}

Como en tantos otros debates, el del corporatismo responde a la necesidad de comprender mejor nuestro entorno y dar respuesta a los problemas más o menos acuciantes que plantea. Quienes venimos participando desde hace tiempo en él, partimos del supuesto de que las democracias desarrolladas han evolucionado de forma que resulta difícil comprender con viejos modelos teóricos. Luego cada cual ha seleccionado determinados cambios y problemas que le han parecido especialmente relevantes para desentrañar el sentido y la forma de esa evolución. Hay, no obstante, un notable grado de coincidencia en los datos y rasgos que se han seleccionado, aunque a la hora de interpretarlos existan diferencias en función de las diversas perspectivas teóricas. Este conjunto de cuestiones constituyen en gran medida las condiciones que han dado origen a las tendencias corporatistas y pueden considerarse causas más o menos inmediatas, necesarias y/o suficientes, de su aparición.

Conocer previamente el ámbito de las preocupaciones sobre las que ha surgido el debate ayudará a comprender mejor el desarrollo que cada línea de interpretación ha tenido posteriormente, así como las relaciones que pueden existir entre ellas. Parece, pues, oportuno que antes de entrar en otros temas aislemos el conjunto de cuestiones sobre las que versa. Lo haremos a través de una breve descripción, sin entrar en la forma en que cada tendencia la interpreta e integra en su análisis. Estas cuestiones las trataremos más adelante.

El crecimiento de las organizaciones ${ }^{8}$. La presencia creciente de grandes organizaciones públicas y privadas ha significado la aparición de nuevos centros de poder sin cuya colaboración los gobiernos pueden ver obstaculizada la aplicación de sus políticas. Es decisivo el papel de las organizaciones privadas en la creación y distribución de la producción de la sociedad; en la regulación de la conducta de sus miembros, en la influencia en las decisiones que afectan a la colectividad y en la articulación y demanda de intereses sectoriales y particulares al margen de partidos políticos.

El crecimiento de las organizaciones ha significado una reformulación del poder en el seno de la sociedad. El poder no es ahora un fenómeno de suma cero. Cada organización, al constituirse, genera una nueva fuente de poder que compite con el de otros. Esta competencia produce tendencias monopolísticas u oligopolísticas como forma de garantizar la hegemonía de una organización en un ámbito determinado. La pugna interorganizativa en este sentido es un fenómeno crucial en todas las sociedades modernas de tradición liberal, es decir, pluralista.

${ }^{8}$ Cfr. nota anterior y, también, S. Giner y M. Pérez Yruela (1979 a). En general, los problemas que se mencionan en este apartado han sido tratados con profusión en la literatura que existe sobre organizaciones que no es posible reseñar aquí. No obstante, pueden verse resúmenes interesantes en $M$. Albrow (1979) y D. Silverman (1971), sobre burocracia y teoría de la organización, respectivamente. 
Las corporaciones, esos nuevos actores sociales, han adquirido protagonismo en todos los ámbitos (economía, cultura y política) y han generado un sistema de relaciones entre ellas y con el Estado característico en la evolución de las democracias desarrolladas. Esta situación plantea problemas de regulación de esas relaciones para hacerlas compatibles con el sistema democrático, de forma que el «poder privado» no pueda imponerse a los intereses colectivos y que su propio funcionamiento interno no pueda impunemente perjudicar al interés público. En el caso de las organizaciones públicas y de las burocracias estatales el problema (ya de antiguo detectado) es su tendencia a convertirse en centros autónomos de poder que ofrecen serias resistencias a su coordinación e integración eficiente en el conjunto de la actividad del Estado. Surge así la cuestión de la difícil gobernabilidad de las sociedades corporatizadas, que examinaremos enseguida.

El debate sobre el corporatismo actual trata de descubrir el modo de crecimiento de algunas organizaciones, las pautas del sistema de relaciones interorganizativas, incluido el Estado, y detectar los problemas que puede plantear y los efectos que puede tener en el funcionamiento de la economía y en la estructural social. Al mismo tiempo, las organizaciones presentan algunos problemas técnicos que interesan al análisis corporatista. La capacidad para integrar bien los intereses de sus miembros, el nivel de control que pueden ejercer sobre ellos para que se asegure la aceptación y cumplimiento de acuerdos, la sintonía entre líderes y socios y la importancia de las disenciones internas afectan a la estabilidad y eficacia de las estructuras corporatistas.

La multiplicidad de intereses. Uno de los cambios más frecuentemente constatados de las democracias desarrolladas es la aparición de una multiplicidad de identidades que ha alterado el alineamiento de las clases sociales en el sentido marxista. Las causas de ello son varias: la división del trabajo, la aparición de nuevas profesiones, la diversificación creciente de la estructura ocupacional, la aparición de minorías estratégicas (algunas, por cierto, cada vez más numerosas) que defienden intereses étnicos, religiosos, culturales, o se agrupan por razones de sexo o edad, la división cada vez más acusada - y no por ello menos bien ocultada - entre quienes «mandan» y «obedecen» o la identidad que se adquiere como miembro de tal o cual organización, que es la que presta a uno el prestigio y el status social ${ }^{9}$.

Esta multiplicidad de identidades entraña una ruptura de la homogeneidad de las clases sociales y el debilitamiento de su fuerza y sentido unitario. En consecuencia, una cierta alteración del conflicto de clases. En cambio, añade una multiplicación de las reivindicaciones y de los conflictos y, por tanto, una complicación mayor de la estructura conflictiva de la sociedad y de las relaciones con el Estado.

$\mathrm{El}$ análisis corporatista tiene en cuenta los problemas que plantea esta mul-

9 G. Lehmbruch (1979 a), p. 53, incorpora estos problemas a su noción de corporatismo. 
tiplicidad de demandas en su preocupación por el sistema de representación de intereses y por la «gobernabilidad» de las sociedades modernas.

La representación de intereses. En la concepción pluralista de la democracia los intereses de los ciudadanos se suponían representados por los partidos políticos y por un conjunto ilimitado de pequeños grupos que trataban de satisfacer sus intereses compitiendo entre sí ante el Estado. En este sistema no era posible establecer criterios para planificar y atender equitativamente las demandas, a la vez que el Estado tenía que enfrentarse a una «sobrecarga» de peticiones que no podía atender con sus escasos recursos.

El análisis corporatista parte de la constatación de la tendencia a la reducción del pluralismo, tanto por la concentración espontánea de los grupos en otros más amplios, funcionalmente especializados y con pretensiones de monopolizar su ámbito de representación, como por la necesidad del sistema político de reducir el número de interlocutores para poder ordenar y planificar la asignación de recursos escasos ${ }^{10}$.

La gobernabilidad. El crecimiento organizativo y la proliferación de grupos de interés ha supuesto la presencia de múltiples unidades colectivas, potencialmente conflictivas por la demanda de sus intereses encontrados. Al mismo tiempo, la política económica keynesiana y su crisis relativa posterior requieren un alto grado de control e intervención del Estado. Para hacer el sistema "gobernable» hace falta una integración social que evite la multiplicidad de conflictos sin salida. Las tendencias corporatistas se identifican en los mecanismos que se han desarrollado, unas veces espontáneamente y otras impulsadas por el Estado, para reducir esa posibilidad corresponsabilizando a los actores sociales, especialmente trabajadores y empresarios, en la toma de decisiones y su aplicación. Esto es, en el desarrollo de un modelo de colaboración frente a otro de confrontación "1.

En otro sentido, la gobernabilidad se relaciona con la necesidad de reducir la «excesiva» influencia adquirida por los sindicatos durante la década de los sesenta y someter sus demandas a niveles compatibles con los problemas de la crisis económica ${ }^{12}$.

Finalmente, la gobernabilidad se refiere también a la necesidad de que la representación de intereses se articule de forma que, efectivamente, unifique la multiplicidad de demandas de las bases mediante su reducción y simplificación, como veíamos antes, así como mediante su integración dentro de cada organización representativa.

Los imperativos del capitalismo en su fase crítica. Desde la posición marxista se relaciona la emergencia del corporatismo con la exigencia del capitalismo de limitar las demandas salariales de la clase trabajadora para facilitar

${ }^{10}$ Cfr. P. Schmitter (1981 y 1983). También, A. Pizzorno (1981) y M. Maraffi (1981).

"Von Beyme (1981); U. Alemann y R. G. Heinze (1981); C. Solé (1984); P. Schmitter (1983), y G. Lehmbruch $(1979 b)$.

${ }_{12}$ J. H. Goldthorpe (1983), pp. 12-13. 
el proceso de acumulación del capital. Para ello es necesario, eliminada la vía puramente represiva que carecería de la legitimidad democrática mínima que exige el sistema liberal predominante, crear procedimientos de cooptación que permitan controlar esas demandas y obligar a los trabajadores a su cumplimiento ${ }^{13}$.

La influencia de la socialdemocracia y el sindicalismo reformista. Desde varias posiciones se acepta que el desarrollo del modelo de colaboración se debe a cambios en las ideas políticas y estrategias sindicales. Respecto a las primeras se resalta la influencia de la socialdemocracia al abandonar la lucha de clases y la confrontación como base de su política. En su lugar ha optado por dar prioridad a los intereses nacionales frente a los de clase. Se impulsa así la integración mutua de los diversos intereses, que se someten al «interés nacional» ${ }^{14}$. En relación a las segundas, también se pone de manifiesto la entrada de los sindicatos en el modelo de colaboración que se interpreta en unos casos como resultado del papel jugado por el Estado, que lo impone. En otros, como producto de una estrategia pragmática y conciliadora de los sindicatos que han participado en él, en la medida en que han obtenido determinados beneficios reales a cambio de ciertas concesiones y de su participación en la toma de decisiones ${ }^{15}$. En muchos casos se ve en la «cuestión sindical» una de las más importantes fuentes de inestabilidad de las tendencias corporatistas, pues estas estrategias no parecen prestarse fácilmente a su consolidación definitiva. La condición subordinada de la clase obrera no parece admitir una domesticación perfecta, ni siquiera bajo condiciones de corporatismo «democrático».

La defensa de los intereses nacionales. El nacionalismo. Además del significado que este hecho tiene en relación con la práctica política socialdemócrata, los intereses nacionales son un dato importante en relación a la posición de cada país en el contexto económico internacional. La necesidad de avanzar posiciones en los mercados internacionales a través de mejoras de la productividad y la competitividad han exigido ajustes en las estructuras productivas nacionales y sacrificios, sobre todo a los trabajadores, que para hacerlos viables en términos de una economía capitalista exigían el modelo de colaboración interclasista ya varias veces citado ${ }^{16}$.

En otro sentido, la emergencia o resurgimiento de nuevos y viejos nacionalismos dentro de los Estados (casos de España o Francia, por ejemplo), aunque es un hecho menos resaltado en el debate, pueden significar una recom-

${ }^{13}$ L. Panitch (1979). Un análisis interesante entre teoría macroeconómica y corporatismo puede consultarse en J. Roca (1983).

${ }_{14}$ L. Panitch (1979) y M. García Pelayo (1977 c) analizan cómo ha evolucionado en este sentido la concepción del Estado en la socialdemocracia. E. Allardt (1984) atribuye a la larga hegemonía de la socialdemocracia en los países nórdicos el desarrollo de la concertación.

15 M. Regini (1983), p. 9.

16 P. Schmitter (1984 a), pp. 14-19; J. T. Winkler (1976). 
posición estructural y hasta un incremento de las tendencias corporatistas ${ }^{17}$, debilitando el corporatismo en Estados centralistas y recreándolo en ámbitos territoriales más reducidos.

La función del Estado. Aunque se trate de un tema ampliamente controvertido, desde el punto de vista teórico, el peso del Estado en la creación de un modelo de colaboración parece fuera de duda. Bien se considere, desde el marxismo, instrumento del sistema económico, bien se considere con autonomía suficiente para balancear los diferentes intereses sociales, a la intervención del Estado se le atribuye una importancia fundamental. En unos casos se ve como impulsor de las tendencias corporatistas y en otros como colaborador privilegiado en la consolidación de las tendencias ya aparecidas en la sociedad civil. De una u otra forma, es incuestionable su intervención creciente en la regulación y dirección de la economía y su influencia casi decisiva en la asignación de recursos para gastos sociales (sanidad, educación, pensiones), para atender las demandas procedentes de los diversas grupos de intereses y para mantener $o$ incrementar el aparato militar.

El papel impulsor del Estado en las tendencias corporatistas se atribuye en unos casos a exigencias estructurales del sistema, que se concretarían en la necesidad de poner bridas a las demandas sociales, limitando y seleccionando el número de las organizaciones de intereses que tienen acceso a ellas, legitimando e incluso concediendo determinado status político sólo a algunas ${ }^{18}$. Esto propiciaría las tendencias monopolísticas en la representación de intereses y sancionaría jurídica y políticamente el acceso a las así seleccionadas a la toma de decisiones. En otros casos se atribuye a razones organizativas. El Estado necesita. «interlocutores válidos» que representen bien a sus afiliados y que sean capaces de controlar la conducta de sus miembros para que se cumplan los acuerdos e incluso las normas generadas por él mismo que les afecten. El cumplimiento de ambos depende de su fuerza jurídica de obligar, pero también, y de forma muy importante, de la disposición de los sujetos afectados para obedecer ${ }^{19}$. He aquí, pues, una posibilidad de reformulación «corporativa» de la teoría clásica de la obligación política.

La concertación social. Quizá sea el rasgo que más ha llamado la atención y que de forma más inmediata ha contribuido a suscitar el debate. Esto no se debe al hecho en sí mismo cuanto a que puede considerarse la culminación del modelo de colaboración. En la concertación se dan cita las organizaciones, relativamente monopolísticas, de representación de intereses. Interviene en muchos casos el Estado como director o mediador de la negociación. Se puede obtener así una definición común, integrada, de los problemas y se transaccionan o se imponen obligaciones y beneficios para las partes en aras de los intereses colectivos y del mejor desarrollo de la economía. Para la mayor parte

${ }^{17}$ S. Giner (1983), V. Pérez Díaz (1985).

${ }^{18}$ C. Offe (1981).

19 T. Daintith (1983). 
de quienes han intervenido en el debate, es ésta la tendencia corporatista por excelencia, aunque ello suponga una visión restringida de la misma en las sociedades modernas.

Como se ve, la preocupación por el modelo de colaboración resalta a través de muchas de las cuestiones que subyacen al debate. Esto no significa que estén ausentes las reflexiones sobre las contradicciones, algunas citadas, que ponen en peligro la consolidación y estabilidad de las tendencias corporatistas. Pero esta constatación de los aspectos integradores pone de manifiesto la semejanza de las tendencias actuales con la vieja tradición «corporativista» precisamente en la visión integrada y conciliadora del orden social. A ello responde la propia recuperación del término para definir la situación actual.

Todas estas cuestiones han sido consideradas de forma distinta en unos casos, y similar o complementaria en otros, por quienes han tratado de ofrecer una concepción más o menos global del corporatismo.

\section{Una nota sobre el uso del término "corporativismo»}

No han existido reticencias para aceptar el uso del término corporativismo al referirse a la confluencia entre los viejos y nuevos fenómenos sociales que han dado origen a este debate. En lugar de reticencias más bien pudiera decirse que ha habido un interés explícito en recuperar el término, ya que se ha extendido su uso sin que hayan surgido intentos de sustituirlos por otro y sin que se haya discutido la pertinencia o no de aceptarlo ${ }^{20}$.

Sin embargo, todos los que lo han utilizado han establecido con claridad desde el primer momento las diferencias sustantivas que hay entre el viejo y el nuevo corporativismo. Diferencias que estriban en su sociogénesis, en los principios latentes y en la extensión del fenómeno en ambos casos. El nuevo corporativismo, a diferencia del otro, tiene una cierta espontaneidad en su origen que no responde totalmente a un diseño realizado desde el poder; coexiste con una concepción pluralista y conflictivista de la sociedad que no puede reducirse a una totalidad armónicamente integrada. Sólo abarca una parte de las relaciones sociales, políticas y económicas y enlaza con un sistema de representación parlamentaria que guarda una estrecha congruencia con los principios políticos del pluralismo liberal.

Estas diferencias son suficientemente importantes como para que el uso del término se venga haciendo con todo género de reservas y matices. A veces se usa la expresión neocorporativismo para ponerlas de manifiesto o calificando al corporativismo moderno como "pluralista» en contraste con el «estatal», que definiría mejor al antiguo. Por otra parte, el uso de un neologismo puede justificarse utilizando la segunda acepción, tanto en inglés como en

${ }^{20} \mathrm{~J}$. T. Winkler (1976) discute este problema en términos del significado antiguo y nuevo de la misma expresión. También, P. Schmitter (1984a), en este número. 
castellano, ya que la incorpora del inglés, del término «corporativo». De acuerdo con la acepción inglesa, la más antigua, el término corporativo significa «perteneciente a una corporación». Y por corporación se entiende "una asociación de individuos creada por la ley o bajo su autoridad que existe con independencia de la existencia de sus miembros y tiene derechos y obligaciones distintos de las de ellos's ${ }^{21}$.

El corporativismo en esta acepción inglesa se refiere de modo muy genérico «a los principios, doctrinas o sistemas de la organización corporativa de una unidad política». El término podría, pues, emplearse para resaltar el protagonismo de las corporaciones $o$, como suele decirse, de las organizaciones formales, en los procesos a los que nos estamos refiriendo, incluido el sistema de relaciones entre ellas. Así podría entenderse de una forma más neutral, libre de las connotaciones político-ideológicas que tiene cuando se emplea la acepción francesa 22 .

En cierta medida ésta es la intención de Schmitter, uno de los que primero trataron el tema en 1974, al argumentar que el uso del término es hoy día posible si se le despoja de esas connotaciones y se define de forma operativa y neutral, y que utiliza normalmente las expresiones corporate y corporatism en lugar de corporative y corporativism. De modo similar sugerimos que en castellano se utilice el término "corporatismo» en lugar de *corporativismo», cosa que nosotros mismos venimos haciendo desde 1977.

De cualquier forma, el uso de la expresión es problemático y por ello no es del todo ociosa esta referencia terminológica. No es fácil despojario de las connotaciones que son, en gran medida, incompatibles con el sistema de democracia liberal. Pesa mucho todavía el referente histórico a través del que este concepto adquirió su contenido. Y para complicar más las cosas, al mismo tiempo conviven el uso tradicional del término con el nuevo. La pervivencia, hasta hace muy poco, de regímenes políticos autocráticos o dictatoriales en América y Europa ha llevado a algunos sociólogos y politógolos a estudiarlos como sistemas corporativistas ${ }^{23}$, mezclándose trabajos publicados con títulos más o menos similares en los que el concepto se usa de forma diferente. $\mathrm{Y}$ también lo es porque, en cierta medida, el corporatismo actual, aunque por procedimientos y con resultados diferentes, consolida el sistema de desigualdad social como lo hiciera el antiguo, aunque de un modo específico diverso ${ }^{24}$.

21 Random House Dictionary (Unabridged Edition, 1973), v. corporation, corporate y corporatism; The Shorter Oxford English Dictionary (1973), v. corporation y corporate; The New Encyclopedia Britannica (Micropaedia, vol. III, 1983), v. corporate state; Diccionario Crítico Etimológico Castellano e Hispánico, de J. Corominas y J. L. Pascual (Madrid, 1980).

${ }^{22} \mathrm{H}$. Elbow (1966).

${ }^{23}$ Por ejemplo, el estudio sobre las dictaduras latinoamericanas de A. S. Miller (1976), F. P. Pike y T. Strich (1974), A. Stepan (1978) o J. M. Malloy (1977).

is. Giner (1983). 


\section{Las definiciones}

A la hora de definir el corporatismo actual en los regímenes liberales democráticos, la atención se ha centrado sobre todo en la forma que adquiere el sistema de representación de los intereses de la sociedad y en la forma en que esos intereses colectivos se articulan con el Estado y son integrados dentro de él para participar y corresponsabilizarse en el diseño de la política económica. Esta delimitación del objeto de análisis aísla, como decíamos antes, una parte de un fenómeno más amplio, reduciendo prácticamente el debate al problema de la concertación económica practicada en los países desarrollados después de la II Guerra Mundial, y sobre todo desde que comenzó la recesión económica, tras 1973. No obstante, representación de intereses y concertación, tal y como se entiende en varias de las aportaciones al debate, son fenómenos complementarios aunque tengan implicaciones y alcances distintos.

En la ciencia política, especialmente anglosajona, las democracias desarrolladas se han venido analizando hasta ahora de acuerdo con el «modelo pluralista», que sustituía, una vez reconocido el relativo «fin del liberalismom, al modelo más próximo a la utopía liberal. A su vez, el modelo corporatista reconoce, de alguna forma, el fin del pluralismo, al que sustituye.

$\mathrm{El}$ modelo pluralista concibe a la sociedad organizada en grupos voluntarios y autónomos de representación de intereses, de naturaleza jurídica privada, que compiten entre sí para la consecución de sus objetivos respectivos. Estos grupos pueden constituirse en número indefinido, solaparse y actuar utilizando un número también indefinido de recursos para influir en las decisiones que les afecten. El sistema político es el resultado de la interacción de estos grupos en la que el gobierno actúa de árbitro sobre la competencia de esos intereses organizados. El Estado queda relegado del análisis, sin que le atribuya una función específica en esa trama. En todo caso, el Estado se concibe como conjunto de instituciones que interactúan con los grupos de intereses ${ }^{25}$.

Schmitter propone una definición de «pluralismo», que recoge los elementos anteriores de forma sistemática ${ }^{26}$. Por referencia a ella desarrolla la de corporatismo como modelo típico ideal del sistema de representación de intereses. Se trata de la definición históricamente más influyente:

«El corporatismo puede definirse como un sistema de representación de intereses en el que las unidades que lo constituyen están organizadas en un número limitado de categorías singulares, obligatorias, no competitivas, ordenadas jerárquicamente y funcionalmente diferenciadas, reconocidas o autorizadas ( $\mathrm{si}$ no creadas) por el Estado y a las que se les

25 M. Maraffi (1981).

26 P. Schmitter (1979), p. 15 (publicado por vez primera en 1974). 
garantiza un determinado monopolio representativo dentro de sus respectivas categorías, a cambio de practicar ciertos controles en la selección de sus dirigentes y en la articulación de peticiones y ayudas» ${ }^{27}$.

A primera vista, el corporatismo así definido supone una «ordenación» del pluralismo. Los grupos son limitados en número, no compiten entre sí, mantienen posiciones jerárquicamente distintas y se articulan sobre funciones diferentes. El Estado interfiere la esfera de libertad en la constitución de esos grupos reconociéndoles cierto status y monopolio representativo a cambio de que ellos ejerzan determinados controles en su funcionamiento interno. La definición pretende ser neutral en el sentido de que no prejuzga si tal sistema se forma espontáneamente o es producto de la intervención estatal o del poder político.

La crítica más generalizada a la definición de Schmitter es que sólo considera una parte del proceso: los intereses. Para nada tiene en cuenta los mecanismos a través de los que esos intereses se realizan, ni el peso y función del Estado en ese proceso ${ }^{28}$. Pero también debe tomarse con reservas en otros sentidos. Esta definición se refiere a un modelo típico-ideal que no está libre de ciertas afinidades con los propuestos por la ideología corporativa, e incluso relativamente fácil de identificar en países en los que el corporativismo ha estado presente hasta hace poco. La cuestión es que en las democracias liberales ese modelo difícilmente podrá presentarse realmente, salvo que cambiase la naturaleza política de esos regímenes. La definición pierde por ello parte de su valor al aplicarse donde se ha consolidado la democracia liberal.

En efecto, es cierto que se observan tendencias hacia la especialización funcional en la representación de intereses: dentro de sindicatos y patronales adquieren cada vez más peso las secciones especializadas por ramas de actividad; también se desarrollan las asociaciones y sindicatos profesionales. Es igualmente cierto que se observa dentro de esta especialización una tendencia hacia el monopolio representativo. Pero esta estructura, basada principalmente en la división del trabajo, no agota el ámbito de los intereses organizados. Junto a ellos podemos situar otras instituciones que también entran en él: ejércitos, iglesias, sectas y grupos de presión organizados en clubes, círculos profesionales y asociaciones. También las corporaciones empresariales y algunas agencias $\mathrm{e}$ instituciones públicas defienden intereses institucionales y movilizan para ello a sus miembros cooptándolos en competencia con otras organizaciones a que podrían pertenecer por criterios profesionales o de clase. $\mathrm{Y}$ todo ello sin entrar, para no confundir nuestro argumento, en la cuestión crucial de la presencia masiva de las grandes compañías privadas o estatales -corporaciones como empresas- en el seno de las sociedades modernas.

${ }^{27}$ P. Schmitter (1979), p. 13.

${ }^{28}$ Respecto \& la primers critics, sf. G. Lehmbevch (1979 b) pp. 149-150. En relación con la segunda, L. Panitch (1980), pp. 106-110, y B. Jessop (1979), pp. 186-188. 
Todos estos intereses organizados interactúan entre sí y con el Estado en una trama compleja de relaciones. Evidentemente, dentro de esa red de influencias mutuas puede existir una jerarquización, pero es difícil avanzar hipótesis acerca de su estabilidad o su forma, porque el reconocimiento de la libertad de asociación abre una puerta a que esa trama se construya y reconstruya al ritmo que lo puedan hacer el propio complejo de intereses organizados. En todo caso, para que la idea de jerarquización no fuese trivial, habría que referirse al «principio jerarquizador» que ordene ese tráfico de influencias, cosa que no incluye la definición. Otras definiciones a las que nos referiremos más adelante sí incluyen tal principio. Por la misma razón anterior, la parte de la definición que se refiere al carácter limitado, obligatorio y singular de los intereses organizados ni es un hecho consumado en estas sociedades, es decir, no ha llegado a producirse espontáneamente de forma tan nítida, ni puede derivarse teóricamente de la libertad de asociación ni de la multiplicación de los intereses en liza.

En cuanto a la intervención del Estado para autorizar, legitimar o crear grupos de intereses a cambio de ciertas concesiones en su funcionamiento interno por parte de ellos, conviene hacer una distinción crucial: es cierto que existen corporaciones u organizaciones de derecho público en las que el funcionamiento interno viene regulado por disposiciones legales a través de las que el Estado podría intervenir en alguna de las formas anteriores. Pero también es cierto que las organizaciones de derecho privado pueden ser igualmente importantes dentro del complejo de la articulación de intereses. En estos casos el Estado tiene sencillamente que reconocerlas como expresión de un derecho constitucionalmente reconocido, sin necesidad alguna de condecerles licencia específica para que existan ni mucho menos delegarles poderes especiales, expresa o tácitamente. En ambos casos tiene que respetar su funcionamiento interno, sobre todo en el ejercicio de la democracia para la elección de dirigentes y la definición de sus políticas en cualquier ámbito de la vida social.

En suma, la definición de Schmitter atribuye a las sociedades que nosotros llamamos corporativas unos rasgos estructurales que de presentarse en algún caso no significarían sólo una evolución de las democracias liberales que mantuviese intactos sus fundamentos básicos (pluralismo político e ideológico, libertad de asociación, división de poderes), sino una auténtica mudanza en la naturaleza de esos regímenes. Esta suposición no se ajusta del todo a la realidad de las sociedades a las que trata de aplicarse. Al contrario, se observa una tendencia al afianzamiento de la democracia liberal como modelo a perfeccionar e incluso a exportar, aunque, al mismo tiempo, se estén generando tendencias corporatistas que entran en contradicción muchas veces con ellas y que, por esta razón, muestran un carácter inestable, confuso y con notables diferencias de unos casos a otros. La lógica de la estructura interna de este modelo, a nuestro juicio, requiere para hacerlo realidad no sólo un cambio en el sistema de representación de intereses, sino también un cambio en la forma 
de Estado. Sin ello el subsistema de representación de intereses difícilmente podría adquirir en las democracias liberales todos los rasgos que en esta definición se le atribuyen.

Este es uno de los problemas que más preocupan en el debate: la forma y el papel que el Estado puede adquirir en el corporatismo actual. O, en otras palabras, la compatibilidad del modelo corporatista con el sistema democrático liberal heredado. Sobre el primer problema existe poco consenso, e importantes lagunas teóricas, lo que hace difícil avanzar conclusiones de aceptación general. Más bien se mantienen posiciones poco reconciliables entre las diversas perspectivas, como veremos más adelante. Sobre el segundo, Schmitter afirma en otro trabajo ${ }^{29}$ - que hemos incluido en esta revista - que la consolidación del corporatismo dependerá de su capacidad para legitimarse en el contexto democrático y que se genere un nuevo orden social que lo integre. La contradicción, pues, se mantiene abierta.

Además, cuando este modelo típico ideal se toma como un conjunto de hipótesis a contrastar empíricamente, como hiciera Blau con el modelo de burocracia de Weber ${ }^{30}$, los resultados conducen a muy diverso grado de acercamiento a ellas, lo que hace difícil su interpretación en términos de este modelo. Por todo esto es explicable el escasísimo acuerdo que existe sobre la definición de corporatismo. Su inestabilidad y variabilidad en cuanto a la forma de presentarse en los diversos casos estudiados y las contradicciones antes indicadas han originado otras definiciones.

A pesar de todas estas matizaciones, esta definición tiene la ventaja, ampliamente reconocida, de haber puesto en términos operativos una noción de corporatismo que ha impulsado el debate teórico y empírico sobre su sociogénesis y sobre el nivel a que estas tendencias se encuentran presentes en las sociedades capitalistas avanzadas. Es más, los fenómenos a que la definición hace referencia (especialización funcional de los grupos de representación de intereses, tendencias monopolísticas en el ámbito de representación y cierta intervención del Estado en la creación y legitimación de los grupos) son reconocidos por la mayor parte de los autores como las cuestiones a investigar para desentrañar el nivel de corporatización existente, es decir, lo que nosotros hemos llamado la densidad comparativa de cada sociedad.

Otras definiciones del corporatismo se centran más en los aspectos de la concertación que en los de la representación de intereses. Se trata de definiciones que se derivan de la evolución de las sociedades desarrolladas, en especial de su situación económica y política, que se formulan en términos menos rígidos que la anterior, y pueden aplicarse a una mayor variedad de casos. Lo que subyace a estas definiciones es la pregunta sobre las condiciones que han hecho posible la integración de los distintos grupos de intereses en la toma de decisiones, cediendo o sacrificando algunas de sus demandas. En todas ellas

29. P. Schmitter ( $1984 a$ ) (incluido en este número).

${ }^{30}$ P. Blau y R. Scott (1963). 
se mantiene implícita o explícitamente la pervivencia del sistema democrático, considerando al corporatismo como un mecanismo de adaptación y de solución de problemas. También aceptan comúnmente algunos de los elementos de la definición de Schmitter en lo que se refiere a las tendencias monopolísticas en el proceso de articulación de intereses y a la intervención del Estado, como condición necesaria para la aparición del corporatismo.

Existe una noción de corporatismo calificado por Lehmbruch como corporatismo liberal ${ }^{31}$ en torno a la que podrían agruparte varias aportaciones al debate. Esta noción parte de la segmentación cultural, política y económica de la sociedad, que se manifiesta en grupos de intereses organizados que resuelven sus conflictos entre ellos mediante la negociación entre sus élites dirigentes respectivas. El corporatismo liberal sería una generalización de este modelo a las relaciones entre el gobierno y los grupos de intereses organizados, en la hipótesis que esto puede contribuir «a la estabilidad y gobernabilidad de las sociedades altamente desarrolladas, promoviendo una nueva forma de integración social» ${ }^{32}$. Esta definición enfatiza la autonomía de los grupos, se basa en la premisa de que son altamente interdependientes y establece como condición decisiva para su viabilidad la creencia de que los intereses en liza no son en última instancia incompatibles, en contra de la concepción marxista de la lucha entre clases irreconciliables. En definitiva, el corporatismo, más que un sistema de articulación de intereses, constituiría «un modelo institucional para la elaboración de políticas en el que las grandes organizaciones de intereses cooperan entre sí, así como con las autoridades públicas, no sólo en la articulación (o incluso mediación) de intereses, sino también en la aplicación de tales políticas» ${ }^{33}$. Se considera que los procedimientos de negociación tienen con frecuencia un carácter más informal, de acuerdo con las circunstancias, que institucionalizado explícitamente al modo del sistema parlamentario, por ejemplo.

Aunque la aportación de Lehmbruch es la más formalizada dentro de lo que él mismo denomina corporatismo liberal, con esta noción conectan los análisis que han insistido en la necesidad de reducir la pluralidad de intereses y desarrollar un modelo más organizado de colaboración entre los actores sociales. Como Lehmbruch afirma, el corporatismo «aparece para regular el conflicto de clases en la distribución de las rentas y en la estructura de las relaciones industriales" ${ }^{34}$, análogamente a lo que sugieren estos otros análisis ${ }^{35}$.

Esta definición se acerca mejor a la realidad del corporatismo actual, que

${ }^{31}$ G. Lehmbruch (1979 a), p. 53.

32. G. Lehmbruch (1979 b), pp. 149-151.

${ }^{33}$ G. Lehmbruch $(1979 b)$, p. 150.

4. G. Lembruch $(1979 b)$, p. 151.

${ }^{35}$ E. Allardt (1984) mantiene una posición muy parecida en su análisis del corporatismo escandinavo, que cree deberse a la tradición de diálogo entre las fuerzas sociales, a la activa intervención del Estado, asumida sin reservas por la sociedad civil, y a los buenos resultados obtenidos en la práctica por la concertación. Para otros puntos de vista, cfr. C. Solé (1984). 
se manifiesta más como una tendencia que como un modelo definitiva y rígidamente consolidado y que se ha manifestado, hasta ahora sobre todo, con gran variabilidad, en el terreno de los llamados pactos sociales en varios paises europeos. No presupone condiciones especiales más allá de la existencia de las organizaciones y sus relaciones de interdependencia. En cierta medida converge con la noción de corporatismo que nosotros mismos hemos desarrollado ${ }^{36}$ en la que entendemos que el corporatismo se caracteriza, en última instancia, por la trama de interdependencias organizativas inevitablemente creada por la proliferación de grandes organizaciones con tendencias monopolísticas u oligopolísticas en sus ámbitos respectivos de actividad.

Una debilidad, empero, de la noción del corporatismo liberal estriba en que por su nivel de generalidad puede ser tan difícil de operativizar como la inicial de Schmitter lo era de aplicar por su mayor rigidez. Pero es más reprochable el que no entre a analizar la conexión entre este sistema de colaboración y los distintos poderes de negociación de quienes participan en él. En definitiva, es menester aún explorar en favor de quién se regulan por este procedimiento los conflictos sobre la distribución de la renta y las condiciones de trabajo: ¿quién gana y quién pierde en los procesos corporativos?, ¿cuál es su lugar en el sistema de desigualdad y de denominación de cada país? Son ésas las preguntas que con demasiada frecuencia soslaya la teoría y la investigación sobre corporatismo - con pocas excepciones- y de modo, quizá injustificable.

La segunda modalidad de este género de definiciones no elude la cuestión. Así, desde el análisis marxista, Panitch concibe el corporatismo como «una estructura política dentro del capitalismo avanzado que integra a los grupos organizados que intervienen en la producción de un sistema de representación y de interacción mutua a nivel de los dirigentes, y en un sistema de movilización y control en el nivel de las masas» ${ }^{37}$. Esta posición es radical en el sentido que niega al corporatismo cualquier posibilidad de beneficiar a la clase obrera, ya que aparece para «contener la fuerza política y económica de la clase trabajadora»..., «haciendo que asuma los criterios del crecimiento del capitalismo... sobre la contención salarial» ${ }^{38}$. Concibe el corporatismo liberal como una estructura política compatible con la democracia, a diferencia del viejo «corporativismo» que tuvo que abolirla, aunque en ambos casos sea para el sometimiento de los trabajadores.

La crítica que debe formularse a esta posición radical es que, salvo que se admita que la «falsa conciencia» de los trabajadores respecto a sus intereses objetivos sea un fenómeno ya de larga duración en los países occidentales, su participación en la concertación tiene que responder al hecho de que aceptan el modelo de colaboración u obtienen alguna ventaja de él. La cuestión es

${ }^{36}$ S. Giner y M. Pérez Yruela (1979).

${ }^{37}$ L. Panitch (1979), p. 123, y (1980), pp. 173-178.

${ }^{38}$ L. Panitch (1981). 
demasiado compleja como para poder ser analizada aquí ${ }^{39}$, aunque en este mismo número Tomlinson aporta una crítica desde la izquierda a la versión marxista del corporatismo.

Finalmente, un tercer tipo de definiciones concibe al corporatismo como una forma de Estado. Así, Winkler lo definió como un «sistema económico en el que el Estado dirige y controla predominantemente los negocios privados de acuerdo con cuatro principios: unidad, orden, nacionalismo y éxito» ${ }^{40}$. Pero esto parece pecar de ingenuo: ni el Estado liberal tiene autonomía suficiente para dirigir de forma tan autoritaria los negocios privados, ni los cuatro principios se diferencian de los que suelen legitimar la concertación: colaboración en lugar de confrontación, es decir, unidad, o de los que desde siempre rigen el capitalismo. Aunque pueda ser, por tanto, exagerado concebir el corporatismo como un nuevo sistema económico diferente del capitalismo o el socialismo, a esta dudosa definición le cupo adelantar, en su momento, algunos de los temas sobre los que luego se iba a centrar el debate: el papel del Estado en la regulación de la economía y la filosofía de colaboración social en beneficio de los intereses nacionales o colectivos practicada en la concertación.

Volviendo a la perspectiva marxista, Jessop define el corporatismo como la forma de Estado apropiada en este momento histórico para la reproducción del capitalismo. El corporatismo surge como un híbrido entre el viejo «Estado corporativo» y la democracia parlamentaria, debido a la crisis política que ésta atraviesa. Esta crisis se concreta en la separación creciente entre el parlamento y la administración pública, que es la responsable, en definitiva, de la ejecución de las políticas de un Estado cada vez más intervencionista. Por esta separación, el parlamento no controla a la administración y, en consecuencia, los intereses representados en él no pueden tampoco controlar la intervención anterior. Por ello surge un nuevo sistema de representación de intereses que entra en contacto con los centros de toma de decisión política sin que medie la representación parlamentaria ni la burocracia administrativa ${ }^{41}$.

La aportación de Jessop, ciertamente compleja, tiene elementos interesantes en lo que se refiere a las limitaciones del sistema parlamentario para representar adecuadamente la multiplicidad de los intereses en liza. La cuestión de las dificultades del parlamento para controlar efectivamente a la administración y al propio ejecutivo era ya conocida. No obstante, en cuanto al sometimiento de todo ese proceso a las condiciones de reproducción del capitalismo, no añade nada a otras definiciones citadas antes.

Sólo hemos recogido aquí algunas de las definiciones que nos parecen más

${ }^{39}$ En cualquier caso, sobre este tema pueden verse, por ejemplo, M. Mann (1978) y C Crouch y A. Pizzorno (1978). Una crítica a la posición de Panitch puede verse en el artículo incluido en este número de J. Tomlinson.

${ }^{40} \mathrm{~J}$. T. Winkler (1976), p. 103. Una definición intermedia entre ésta y la de Schmitter puede verse en $A$. Cawson (1978).

${ }^{4}$ B. Jessop (1979). 
representativas para reconstruir el hilo del debate. De la variedad de enfoques se deduce el escaso grado de acuerdo respecto a qué es exactamente el corporatismo, como se ha puesto de manifiesto. Ello no permitiría avanzar muchas conclusiones sobre el estado actual del debate. No obstante, creemos que hay un conjunto de elementos comunes, suficientemente relevantes, que pueden constituir una aproximación mínima a lo que pueda ser el fenómeno. De ello nos ocuparemos más adelante.

\section{Las modalidades del corporatismo}

Es habitual la referencia dentro del debate a que el corporatismo actual en las democracias desarrolladas responde a procesos espontáneos y autónomos dentro de la sociedad, sin que exista un diseño «desde arriba» para construir ese modelo de colaboración. Aun en el caso de los análisis marxistas, no puede demostrarse la imposición del modelo a ninguna de las partes, aunque es cierto que desde el Estado se han creado las condiciones jurídicas y políticas para facilitarlo y que, en todo caso, contribuye a la consolidación del sistema de desigualdades existentes. A este tipo de corporatismo se le ha denominado societal, liberal o pluralista. Por contraste, se define el corporatismo estatal, autoritario o monopolista ${ }^{42}$, incompatible con el sistema democrático, que se identifica con el viejo corporativismo, con el practicado en dictaduras más recientes o con el que pudiera darse dentro de un sistema cerrado. A cada tipo se le considera, en ocasiones, como un modelo histórico propio de fases diferentes en la evolución del capitalismo, aunque para la tendencia radical dentro del debate haya cumplido funciones semejantes en ambos casos, por lo que algunos consideran que sustancialmente se trata de la misma clase de fenómeno ${ }^{43}$.

Las modalidades de corporatismo no se reducen sólo a meras clasificaciones o tipologías como las anteriores. Además de considerarse vinculadas, como acabamos de decir con diferentes etapas del capitalismo, cada modalidad se asocia más o menos directamente a una determinada forma de orden social. En el caso de las versiones liberal y radical, el corporatismo actual se considera como una adaptación del sistema liberal democrático a la complejidad organizativa del Estado y la sociedad civil, que no altera sustancialmente los principios básicos de ese orden político. Schmitter, sin embargo, ha tratado de conectar el corporatismo actual a un orden social que llama «asociativo" y que define por contraste a otros órdenes, que denomina, respectivamente, «comunidad», «mercado» y «estatal»"

4 Schmitter lo clasifica como «societal» o *estatal»; Lehmbruch, como «liberal»; Panitch, como «autoritario* y «liberal», y nosotros, como *monopolista» y «pluralista». García Pelayo, sin entrar propiamente en el debate, clasifica las relaciones entre sistema organizacional y sistema político como «monocéntricas» y *pluricéntricas».

${ }^{43}$ Esta parece ser la posición de Martínez Alier (1985).

4 P. Schmitter (1984 a) (incluido en este número). 
Lo característico del «orden asociativo» es que sus principios básicos no se derivan de los vínculos primordiales de la comunidad, ni de las relaciones competitivas e impersonales del mercado, ni de la imposición de un sistema cerrado de relaciones diseñado por el Estado. Se derivan de la presencia de las organizaciones como nuevos factores sociales y del intercambio entre ellas. Esta trama se construye por la especialización funcional de aquéllas y sus tendencias monopolísticas u oligopolísticas, el reconocimiento mutuo del poder de cada organización para influir en las decisiones de las demás, la institucionalización de foros para las negociaciones y las segmentaciones que se producen por la pertenencia a una u otra organización, por la condición de dirigente o dirigido y por las rivalidades entre grupos peor o mejor organizados, de ámbito local o nacional y de intereses étnicos, religiosos o culturales distintos 45 .

De forma más genérica, nosotros mantuvimos ya antes una posición similar al definir la sociedad corporativa como «toda aquella en la que los modos de estructuración fundamentales, los de conflicto y los de orden clasista, de poder y de prestigio, rigen y se ejercen a través de corporaciones» ${ }^{46}$. De igual modo contrastamos en el mismo lugar este nuevo orden emergente con los diversos órdenes históricos precedentes.

\section{Causas y condiciones del desarrollo corporatista}

Al hablar antes de la sociogénesis del corporatismo dimos cuenta de un conjunto de cambios concomitantes con el desarrollo de las tendencias corporatistas que, en un sentido muy amplio, podrian considerarse causas y condicionantes de ese desarrollo. Ordenando más esas ideas en relación a las diversas tendencias dentro del debate, pueden aislarse los siguientes argumentos de causación.

El que tiene un ámbito más general de aceptación, es el que interpreta al corporatismo como resultado de ciertos imperativos o necesidades del capitalismo para reproducir sus condiciones de existencia y hacer más manejable y controlable el desarrollo de la economía en su favor. La noción parece circular o hasta tantológica, pero, al margen del problema que ello supone, constituye un supuesto general, cuyas interpretaciones divergen inmediatamente en las versiones liberal y radical.

Para la versión liberal el argumento del imperativo capitalista no constituye tanto una causa directa cuanto un desarrollo mutuamente condicionante entre los dos procesos: evolución del capitalismo y desarrollo del corporatismo. Este último, en lo que significa de tendencia monopolística u oligopolística en la representación de intereses, se ha visto impulsado por las exigencias

13 W. Streeck y P. Schmitter (1983), p. 13.

* S. Giner y M. Pérez Yruela (1979), p. 13. 
del sistema político de ordenar las demandas sociales y racionalizar el proceso de asignación de recursos. La fusión de ambos procesos en la concertación es una suerte de feliz coincidencia que se produce por razones pragmáticas, por la eficacia de ese procedimiento para regular el conflicto de clases en beneficio del interés general y, por consiguiente, en beneficio de todas las partes ${ }^{47}$. Esta coincidencia también se interpreta, en otros términos, como el avance de la racionalidad de la burocracia y de la sociedad organizada que históricamente parece acompañar a la evolución de la democracia ${ }^{48}$. O como el resultado indirecto de una estrategia de intercambio desarrollada por las organizaciones entre sí y con el Estado, con objeto de obtener determinados beneficios a cambio de ciertas concesiones. Esta práctica habría conducido, por su repetición y afianzamiento, al modelo de concertación ${ }^{49}$.

Este planteamiento remite, si queremos profundizar más en la argumentación, a las causas del propio desarrollo de ambos procesos. Por lo que se refiere al desarrollo del corporatismo en el sentido dado más arriba, parece que la causa de su desarrollo se relaciona con la tendencia social de un amplio alcance a la integración de los individuos en formas de acción social colectiva, en suma, a la revolución organizativa ${ }^{30}$; revolución que, a su vez, se explica tanto por la adquisición del derecho de libre asociación como por las ventajas que las organizaciones ofrecen en diversos órdenes: consecución de bienes públicos o colectivos, desarrollo de la producción, aumento de la influencia social, capacidad para la defensa de intereses comunes y satisfacción de necesidades psicológicas de los individuos ${ }^{51}$.

En cuanto a la evolución del capitalismo, la argumentación se centra principalmente en el modelo de política económica keynesiana seguido por la mayor parte de los países desarrollados después de la II Guerra Mundial ${ }^{52}$. Este enfoque supone una intervención del Estado para mantener el nivel de la demanda y asumir los costes sociales del sistema y, en momentos de crisis, requiere un control estricto de la inflación y de los costes salariales para facilitar la acumulación de capital que, se supone, aumentará el nivel de inversión reduciendo el desempleo. Para hacer eficaz este modelo es menester que los actores sociales colaboren entre sí y con el Estado a través de la concertación. Aunque, como se ha puesto de manifiesto en el estudio de algunos

47 G. Lehmbruch (1979a).

${ }^{6} \mathrm{P}$. Schmitter $(1984 b)$, p. 26 , recoge esta interpretación como predominante en los países escandinavos. Cfr., también, E. Allardt (1984).

${ }^{49} \mathrm{M}$. Regini (1983) interpreta el corporatismo en términos de un sistema de relaciones de intercambio entre organizaciones que se produce en la medida en que cada parte obtiene beneficios en la negociación. Para un análisis de las estrategias negociadoras y de los elementos conflictivos de tales procesos, cfr. Walton y McKersie (1965) y D. Casado y M. Pérez Yruela (1975). B. Nedelman y K. G. Meier (1979) proponen también una interpretación del corporatismo en términos de interacción organizativa que permita analizar flexiblemente, según cada caso, las formas que presenta.

${ }^{50}$ P. Schmitter (1984 b), pp. 28-29.

${ }^{51} \mathrm{M}$. Olson (1965).

$52 \mathrm{~J}$. Roca (1983). 
casos, ésta no sea una condición indispensable, ni este modelo, como prueba el caso español, demuestre ser todo lo eficaz que se supone ${ }^{53}$. En este desarrollo ha tenido una influencia decisiva la socialdemocracia al haber abandonado el enfrentamiento y la lucha de clases como motor del cambio y haberse comprometido en una política de pleno empleo y creación y mantenimiento del «Estado del bienestar». Además de todo esto, también se ha planteado una interpretación compleja, multicausal, en la que intervienen todos los elementos anteriores, que se relacionan de forma variable y poco lineal, según la coyuntura y los avatares de cada sociedad concreta ${ }^{54}$.

Para la versión marxista, en cambio, la relación causal entre corporatismo y evolución del capitalismo es más nítida. Por un lado, se considera que el sistema de representación de intereses, sus tendencias monopolísticas y su legitimación por el Estado tiende a ser, como dice Offe, «predominantemente un tema de "diseño político" y, por tanto, es más una variable dependiente que independiente de las decisiones políticas públicas» ${ }^{55}$. Esta hipótesis puede resumirse en los siguientes términos: la experiencia histórica ha «enseñado» al capitalismo que los grupos de intereses pueden interferir las políticas públicas disfuncionalmente, aunque también sean indispensables para la forma. ción y ejecución de tales políticas, ya que disponen de información y pueden controlar a sus miembros. Por tanto, la tendencia será a integrar esos grupos en la toma de decisiones en condiciones jurídicas y organizativas que garanticen que sus miembros no puedan obstaculizar la aplicación de esas decisiones ${ }^{56}$. Por otro lado, como ya vimos, la estructura política corporatista no es más que la forma en que se produce esa integración a nivel estatal para asegurar las condiciones de reproducción del capitalismo.

De los argumentos anteriores se derivan un conjunto de condiciones técnicas, necesarias para la consolidación del corporatismo. La centralización organizativa, la disciplina interna de las organizaciones para hacer que sus miembros cumplan los acuerdos, los procedimientos para garantizar la estabilidad de la organización y de sus dirigentes frente a las disensiones internas, los criterios para la formación de las organizaciones (sectoriales, transectoriales, funcionales) y la forma en que el Estado les atribuya status público, capacidad representativa y ámbito de participación en la toma de decisiones, son algunas de estas condiciones. En este tema la teoría y el debate han progresado poco, limitándose en la mayor parte de los casos a señalarlas y a formular unas pocas hipótesis que, en la práctica, no se han confirmado. Por ejemplo, la hipótesis de que la centralización organizativa y la cohesión interna contribuyen a facilitar la concertación y a eliminar conflictos parece que es una causa

53 J. Roca (1982) y A. Pappalardo (1983).

${ }^{54}$ P. Schmitter $(1984 b)$, pp. 29-30. En este trabajo parece que revisa algunas de sus posiciones y opta por plantear este tipo de explicación.

${ }^{55}$ C. Offe (1981), p. 125.

${ }^{56}$ C. Offe (1981), passim. 
necesaria, pero no suficiente ${ }^{57}$. O la hipótesis más general del corporatismo de que los acuerdos extraparlamentarios, vía concertación, han sido imprescindibles para la dirección de la economía, según lo expuesto antes, tampoco parecen confirmarse del todo ${ }^{58}$. El ejecutivo y el parlamento pueden tomar decisiones que produzcan resultados similares, sin utilizar la concertación. La política extramural existe, pero no hay razones suficientes para considerar que deba acapararlo todo en las democracias liberales actuales ni que sus parlamentos, partidos y gobiernos no puedan recuperar los espacios que la representación popular les otorga.

\section{Corporatismo, Estado y sistema democrático}

Uno de los temas más controvertidos y sobre los que menos luz se ha aportado en el debate es de las relaciones entre corporatismo y Estado en el sistema democrático liberal. No obstante, todas las versiones del corporatismo lo consideran tema fundamental. La versión marxista critica a la libertad porque en sus definiciones está ausente el Estado o se le atribuye implícitamente cierta autonomía y neutralidad respecto a los intereses de clase ${ }^{59}$. Por su parte, la versión liberal acusa a la marxista de manejar un concepto instrumental del Estado y atribuirle unas funciones al servicio del sistema económico capitalista que no pueden justificarse empíricamente ${ }^{60}$. Pero, a su vez, ambos coinciden en sus respectivos análisis en considerar al Estado en alguna posición intermedia atribuyéndole una cierta capacidad para atender demandas sociales que no benefician sólo a los intereses capitalistas o que contribuyen a la consolidación del capitalismo atendiendo al mismo tiempo otros intereses sectoriales o colectivos, aunque indirectamente sean también en beneficio de aquél.

Schmitter ha abordado directamente esta cuestión ${ }^{61}$ y puede constituir una muestra de esas posiciones intermedias que entroncan con la versión liberal y que, por cierto, se contradice o complementa a otras que mantuvo previamente en las que conectaba al corporatismo con «ciertos imperativos básicos o con ciertas necesidades del capitalismo para reproducir sus condicio. nes de existencia» "2. En el contexto de las relaciones con el Estado, entiende el corporatismo como resultado del «intercambio político» entre organizacio nes privadas y estatales, que no responde a un acto deliberado del Estado para controlar los intereses de los grupos y clases sociales. Este intercambio

57 G. Lehmbruch (1983) y A. Pappalardo (1984).

s8 A. Pappalardo (1983).

99 L. Panitch (1981), pp. 21-28, y B. Jessop (1979), pp. 185-190, ofrecen versiones de esta crítica. También, J. Westergaard (1978).

${ }^{\infty}$. P. Schmitter (1984 b), pp. 27-28, y (1984 a), passim.

${ }^{61} \mathrm{P}$. Schmitter (1984a).

a2 P. Schmitter (1979), p. 24. 
es posible porque las partes que intervienen en él tienen poder suficiente para impedir que la(s) otra(s) pueda(n) realizar sus intereses unilateralmente a través de la explotación económica y cada una, a su vez, es suficientemente débil como para imponer sus intereses indirectamente a través del Estado. Por ello, éste adquiere una cierta capacidad de influir autónoma y unilateralmente en la negociación y el compromiso de intereses. Esta autonomía no está basada en imperativos funcionales para el sistema económico, sino que tiene carácter estructural y se basa en los intereses institucionales del Estado.

Pero el análisis de esos intereses institucionales es más problemático. No son los intereses de los actores integrados en el Estado, gobierno y funcionarios, los que entran en juego. Los define, en primer lugar, por las relaciones de interdependencia con otros Estados, por la competencia internacional y, en el interior, por el atributo más importante del Estado: el ejercicio de su legítima autoridad para someter los intereses sectoriales a los institucionales. Por ello, concluye, el corporatismo tiene más probabilidad de emerger donde la hegemonía de una clase ya no es posible; en los países pequeños, sometidos en su economía a fuerte competencia externa, o los que están en posición de inferioridad en el contexto internacional; en áreas o sectores donde la desorganización o la conflictividad los hace ineficaces.

Esta interpretación es una mezcla entre la reificación del Estado como institución autónoma portadora de intereses universales y lo que nosotros hemos llamado «ley de expansión corporativa» ${ }^{63}$. Según esta «ley», la concentración de poder en algunos Estados u organizaciones en el contexto internacional obliga a quienes quieran competir con ellos a aumentar su grado de corporatización para, a través de él, aumentar la eficacia, la centralización y el consenso y evitar que los conflictos internos debiliten su competitividad en el contexto internacional. Lo mismo puede decirse de las organizaciones dentro del contexto nacional.

Lo mismo que Schmitter, aquí nosotros ya habíamos interpretado el proceso de corporatización actual como resultado de la trama de relaciones de colaboración y competencia que se establece entre organizaciones autónomas con poder de negociación suficiente para obligarse mutuamente al establecimiento de esas relaciones. La «ley de expansión corporativa» es resultado de las relaciones de competencia dentro de esa trama, tanto en el nivel nacional como en el internacional. Simplificando, esta «ley» expresa el principio «corporatizarse o morir» que obligan a poner en práctica ciertas condiciones de la modernidad en algunos países.

Pero todo esto no permite separar los intereses institucionales del Estado de los de las clases y grupos sociales. El contexto internacional tampoco permite separarlos. Al contrario, dada la división en dos bloques de las áreas de influencia internacionales, quienes pertenecen a uno de ellos están dentro de un sistema económico determinado y están sometidos a la hegemonía que

${ }^{63}$ S. Giner y M. Pérez Yruela (1979), pp. 65-88. 
en todos los órdenes ejercen los países líderes de cada bloque. Por tanto, difícilmente pueden los intereses institucionales de un Estado enfrentarse a los principios que rigen su propio bloque. Estos se desarrollarán simplemente en el sentido de fortalecerlos o converger con ellos. La relativa autonomía del Estado tiene, pues, muy pocos grados de libertad para alterar los supuestos básicos en que se basa el sistema económico capitalista, aunque sí pueda utilizarlos para aliviar el sistema de desigualdades que genera.

Para la versión marxista, la posición intermedia reconociendo la relativa autonomía del Estado es más una aceptación inevitable de la realidad que el resultado de un análisis teórico consistente sobre el Estado en el capitalismo contemporáneo y concretamente en el contexto del desarrollo corporatista ${ }^{64}$. En el análisis que Panitch hace de la cuestión parte del supuesto de que el ámbito estatal ni está completamente separado de la sociedad civil ni abarca a todas las instituciones involucradas en la reproducción del capitalismo. Ese ámbito no puede definirse a priori y su expansión depende de la lucha de clases. Las estructuras corporatistas de concertación pueden considerarse una instancia a la que el Estado trata de expandir su ámbito de actuación involucrando a la clase trabajadora en la legitimación de su política económica. Será, pues, la actitud de los sindicatos, incorporándose o no a la negociación, la que permitirá que esta expansión sea o no posible. Por motivos diversos, los sindicatos han permitido en unos casos que la concertación sea posible y en otros no han colaborado en ella. Según esta experiencia, el corporatismo es esencialmente inestable, porque a medio y a largo plazo la clase trabajadora se resistirá a legitimar y aceptar políticas económicas y, sobre todo, salariales que no le benefician y el Estado tendrá que utilizar otras alternativas para hacerlas valer. Se niega, pues, la posibilidad de que la incorporación de la clase trabajadora en el Estado a través de las estructuras corporatistas pueda proporcionarle ventaja alguna, aunque no puede negar el hecho de que esta incorporación se ha producido en muchas ocasiones ${ }^{65}$.

Térciando en el debate, Colin Crouch ha entrado en la discusión sobre el papel del Estado en las democracias liberales intentando demostrar que aquél puede atender demandas que no conduzcan necesariamente a la reproducción del capitalismo, aunque a éstas no pueda obviarlas. Su crítica a la posición marxista parte de que la rigidez en la concepción del capitalismo y de los intereses de clase le impiden reconocer la posibilidad de que el Estado no sea un mero instrumento del sistema económico, y que tenga dificultades para resolver la cuestión de por qué el Estado responde sólo a las necesidades del capitalismo ${ }^{66}$.

Dentro de la tradición del constitucionalismo se mantienen posiciones similares, anteriores a esta formulación. Así, Manuel García Pelayo, en su con-

54 L. Panitch (1981), pp. 21-23.

${ }^{65} \mathrm{~L}$. Panitch (1981).

${ }^{66}$ C. Crouch (1979). 
cepto de «Estado social», plasma la evolución del Estado contemporáneo en el sentido de que va asumiendo una responsabilidad creciente para «neutralizar los efectos disfuncionales de un desarrollo económico y social no controlado» ${ }^{67}$. La constatación del aumento de la complejidad organizativa de la sociedad civil y de la influencia del Estado en la estructuración de la sociedad significan para García Pelayo «una tendencia a la estatización de la sociedad... y a la socialización del Estado y, por tanto, a la difuminación de límites entre ambos términos» ${ }^{68}$. Los efectos de estas tendencias se manifiestan en las funciones reguladora y distribuidora del Estado y en haber incorporado a sus objetivos al integrar los intereses antagónicos de la pluralidad de grupos de la sociedad. Por tanto, considera que en la propia naturaleza del «Estado social» se encuentra la posibilidad de que éste atienda a los intereses de todos los grupos y no sólo a los de una clase social. Esto se facilita por el acceso de las distintas organizaciones de intereses a los centros de decisión estatales ${ }^{69}$ y acerca la posición del politólogo español a una concepción «societaria» del corporatismo.

Parece, pues, que en sus relaciones con el Estado el corporatismo puede, en el mejor de los casos, contribuir a que a través de la concertación los trabajadores puedan obtener algunos beneficios que compensen las desventajas de las relaciones de mercado y, al mismo tiempo, el capitalismo asegure un desarrollo pacífico, gobernable, de su actividad. En cuanto a la relación con el sistema parlamentario, liberales y marxistas coinciden en que el ámbito de la representación parlamentaria es insuficiente para asumir la multiplicidad y especificidad de las nuevas demandas sociales ${ }^{70}$. El corporatismo surge así como estructura diferenciada para canalizarlas, que sustrae al control del parlamento decisiones importantes y los mecanismos de aplicación que se acuerdan directamente entre las organizaciones públicas y privadas, pero que no es incompatible con él ${ }^{71}$. No obstante, éste es otro de los temas en los que el debate ha avanzado poco y en el que se plantean problemas en torno a la legitimidad democrática de los procedimientos corporatistas.

${ }^{67}$ M. García Pelayo (1977 a), p. 23.

6t M. García Pelayo (1977 a), p. 25.

${ }^{69} \mathrm{M}$. García Pelayo $(1977$ b), pp. 92-107. y 195

${ }^{70}$ G. Lehmbruch (1979 b), pp. 147-157; L. Panitch (1979); B. Jessop (1979), pp. 193

${ }^{1}$ P. Schmitter (1984 b), pp. 40-57; A. Pappalardo (1983) sostiene que los partidos políticos mantienen un considerable grado de capacidad de decisión frente a las estructuras corporatistas de concertación, en este estudio comparativo entre Inglaterra, República Federal Alemana y Austria, sobre la respuesta de los distintos gobiernos a la crisis económica. Sobre los problemas de índole constitucional que esta cuestión plantea, cfr. M. García Pelayo (1977 c) y C. Anderson (1977). 


\section{La inestabilidad del corporatismo}

La versión marxista es la que con más insistencia ha puesto de manifiesto la escasa estabilidad del corporatismo. A partir del análisis de clase augura un rechazo de la clase trabajadora a las fórmulas de concertación, como de hecho ha sucedido en diversas ocasiones ${ }^{72}$. Esto no significaría, sin embargo, inestabilidad en las tendencias monopolísticas del sistema de representación de intereses o del desarrollo organizativo.

En la versión liberal, más que de inestabilidad, se habla de precariedad, débil grado de institucionalidad o variabilidad en las prácticas corporatistas ${ }^{73}$. En realidad, si consideramos el corporatismo como el producto de las relaciones de intercambio entre organizaciones autónomas, inevitablemente abocadas a negociar entre ellas, es difícil pronosticar un modelo estable que vaya más allá de la propia situación de negociación. El proceso negociador se desarrollará en función de gran cantidad de variables, tales como los temas a negociar, el poder de negociación de las organizaciones, las estrategias de negociación seguidas, la definición más o menos común de los problemas entre las partes e incluso la voluntad de cada parte para alcanzar un acuerdo en función de los resultados esperados ${ }^{74}$. Todo esto, a su vez, vinculado a los problemas intraorganizativos de cada grupo, a los que ya hemos hecho referencia. Por tanto, se justifica la casi imposibilidad de llevar el modelo corporatista de concertación más allá de la situación negociadora. Lo cual pone de manifiesto que los efectos finales de la corporatización en este ámbito son una cuestión relativamente abierta sobre la que no puede predecirse demasiado.

La inestabilidad en el sistema de representación de intereses puede proceder de varios problemas. Las relaciones entre élites dirigentes y miembros de base es una fuente potencial de conflictos cuando éstos no se consideren bien representados y defendidos por aquéllos. El riesgo de la ruptura de la unidad organizativa, la retirada del apoyo a los líderes o la indisciplina interna son riesgos nada desdeñables. La aparición de nuevos grupos de intereses puede alterar la estabilidad del sistema de representación de intereses, sobre todo cuando aquéllos no encuentren o no se les permita el acceso a los centros de toma de decisiones o las mesas de negociación. Y estos grupos pueden surgir no sólo ex novo, sino como resultado de la incapacidad de las organizaciones existentes para representarlos adecuadamente. Las tendencias a la demanda de descentralización y participación más directa de los ciudadanos significarán una amenaza a las tendencias monopolísticas en este ámbito. Las posibilidades desiguales de acceso y poder de negociación de las organizaciones pueden desencadenar conflictos entre ellas que dificulten la viabilidad de los acuerdos.

72 L. Panitch (1981), p. 35; B. Jessop (1979), pp. 197-200.

${ }^{73}$ G. Lehmbruch (1979 b), p. 151.

74 A. Pappalardo (1983). Este análisis comparativo puede ser ejemplo de tal tipo de problemas. 
Por otra parte, hemos sostenido en otro lugar ${ }^{75}$ que el corporatismo está reestructurando la sociedad, estableciendo nuevas identidades según la posición que los sujetos ocupan en el sistema jerárquico, la diferencia de prestigio de las organizaciones a las que se pertenece o la propia situación de sujeto incorporado o perteneciente a los colectivos todavía no organizados ${ }^{76}$. Estas nuevas desigualdades, que se superpondrán a otras ya existentes, generarán conflictos, como de hecho sucede ya con el aumento de la marginación, que aún no podemos prever.

\section{Conclusión}

De toda la discusión anterior y de otras aportaciones y aspectos que, por razones de espacio, no hemos podido recoger a pesar de su utilidad, creemos que pueden extraerse algunas conclusiones sobre el estado actual del debate sobre el corporatismo que reflejan un posible común denominador de supuestos compartidos:

a) El corporatismo es una tendencia en las sociedades democráticas desarrolladas que tiene unas pocas pautas comunes, presentándose en los demás con gran variabilidad según cada sociedad concreta. Esas pautas comunes no se han desarrollado con igual intensidad en todos los casos.

b) Es común a esta tendencia histórica una reestructuración del sistema de representación de intereses a través de organizaciones especializadas según diversos criterios sectoriales o transectoriales, con tendencias monopolísticas en sus funciones representativas, y reconocimiento más o menos privilegiado por parte del Estado y de otras organizaciones como interlocutores cualificados por su representatividad.

Es, igualmente, común la aparición de grandes organizaciones en todos los ámbitos, tanto en la esfera pública como privada.

c) El proceso anterior puede atribuirse a una doble causación: de un lado, a lo que se ha llamado la revolución organizativa y, de otro, a la creciente influencia del Estado y a exigencias estructurales que han jugado un papel inductor $y$, a veces, creador de tal proceso.

d) $\mathrm{La}$ interdependencia entre las organizaciones parece un hecho inevitable, dado el poder de interferencia y de negociación de cada una respecto a las otras $\mathrm{y}$, por consiguiente, la pérdida de autonomía para actuar unilateralmente en asuntos que afecten a las demás, íncluidas las organizaciones estatales.

e) También es común a la tendencia corporatista, en sentido complementario a los puntos anteriores, la institucionalización de negociaciones y

"s S. Giner y M. Pérez Yruela (1979), pp. 53-63, y S. Giner (1981).

76 S. Giner y M. Pérez Yruela (1985). 
acuerdos entre gobierno, patronal y sindicatos en materia de política económica y, sobre todo, de salarios. Es decir, la práctica de la concertación.

Con carácter más general, es igualmente común la colaboración entre el Estado y las organizaciones privadas en la toma de decisiones y ejecución de las mismas sobre cuestiones diversas.

f) La concertación, y la reestructuración del sistema de representación de intereses, parece que se relaciona con una serie de problemas tales como:

- La necesidad del sistema económico capitalista de contener las demandas salariales para mantener la acumulación de capital y el crecimiento económico en beneficio de la colectividad.

- La necesidad de racionalizar la toma de decisiones y de implicar en ella a los que han de cumplirlas para garantizar que, efectivamente, se consiga.

- La necesidad de reducir la multiplicidad de intereses y de conflictos para asegurar la gobernabilidad.

- La necesidad de contener el poder sindical en el sistema capitalista.

Al mismo tiempo, ambos procesos se han visto reforzados por:

- La influencia de gobiernos socialdemócratas.

- La influencia del sindicalismo reformista.

- La experiencia de la crisis económica de 1929 y de otras subsiguientes.

- La influencia de una visión más integradora e interdependiente de la posibilidad de solución de los conflictos sociales.

- La influencia de la política económica keynesiana.

g) Al Estado se le reconoce una función crucial en este proceso como inductor y sostenedor del mismo, desde una posición de relativa autonomía respecto de los distintos intereses sociales y con una cierta capacidad para atender demandas que amortigüen el sistema de desigualdades generado por el capitalismo.

b) El sistema de representación de intereses y la concertación son estructuras paralelas al de representación y control parlamentarios, al que se le reconoce incapaz de asumir todas las demandas sociales frente al Estado, sin que se haya profundizado en el análisis de la posible incompatibilidad de ambos sistemas.

i) Simplificando la situación, existen dos versiones de estas tendencias: la liberal y la marxista (con sus ramificaciones respectivas), que difieren fundamentalmente en cómo conciben y definen la naturaleza de esta tendencia, en la interpretación que dan a su origen, en el papel que atribuyen al Estado y en la evaluación de a quién beneficia y a qué objetivos sirve finalmente el corporatismo.

i) Se distingue el corporatismo liberal del estatal o autoritario, que se identifica con el «viejo corporatismo». El liberal no responde a un diseño po- 
lítico desde arriba, sino a una multiplicidad de causas concurrentes que surgen de la evolución de la sociedad civil, del Estado y del sistema económico capitalista.

k) Las tendencias corporatistas no presentan un modelo completamente estable ni irreversible. La concertación está amenazada por la negativa de los grupos de intereses a entrar en ella cuando no les favorece o por la acción del Estado cuando tampoco tenga interés en facilitarla. El sistema de representación de intereses está sometido a conflictos por las nuevas desigualdades que genera, que pueden conducirle, según la coyuntura histórica, a períodos intermitentes de desarticulación y recomposición. Por lo tanto, como proceso histórico, el corporatismo no es lineal ni es previsible en cuanto a su futuro a largo plazo.

En este conjunto de proposiciones harto resumidas conviene distinguir un aspecto que consideramos fundamental: la doble visión del corporatismo. Por una parte, se entiende como producto de la reestructuración del sistema de representación de intereses y de la revolución organizativa y, por otra, como la emergencia del modelo de colaboración ejemplificado en los pactos sociales. Aunque conectadas entre sí, se trata de dos tendencias muy distintas en su alcance ${ }^{77}$.

La primera es una tendencia que se viene desarrollando desde hace tiempo con el crecimiento de la burocracia estatal, la concentración industrial, el crecimiento de los sindicatos, las organizaciones transnacionales e internacionales públicas y privadas $\mathrm{y}$, en general, con el surgimiento de todo tipo de asociaciones. En definitiva, con el desarrollo de la sociedad organizada en el sentido de estructurada a través de organizaciones formales que incorporan un número creciente de ciudadanos. Esta es una tendencia de gran alcance y efectos imprevisibles sobre las sociedades en las que se está desarrollando, que está alterando la estructura social, la distribución del poder, del prestigio, de la desigualdad y los mecanismos de toma de decisiones en casi todos los ámbitos.

Frente a esto, el fenómeno de la concertación social puede analizarse de dos formas. Desde una perspectiva coyuntural, relacionada con la crisis económica o la evolución reciente del capitalismo y orientada a analizar sus relaciones con estos problemas. $\mathrm{O}$ desde una perspectiva más amplia, basada en la interdependencia organizativa, tanto a nivel nacional como internacional, de la que la concertación sería sólo un caso. La interpretación del mismo fenómeno sería diferente de utilizar una u otra perspectiva, como de hecho se ha puesto de manifiesto en algunos de los pasajes anteriores.

En el debate actual sobre el corporatismo, además de la confusión frecuente entre ambos fenómenos, se ha optado por analizar, a veces hasta el

${ }^{77}$ P. Schmitter (1982) hace énfasis en esta distinción tratando de establecer los nexos de unión entre ambas. 
último detalle para obtener conclusiones poco relevantes, el tema de la concertación en el contexto de la crisis económica. Lo cual, por otra parte, es perfectamente legítimo. Da la impresión de que se ha pasado de una forma demasiado lineal del pluralismo al corporatismo, y de aquí a la concertación social, cuando en realidad ambos pasos, y especialmente el segundo, son problemáticos.

Quizá algunas de estas lagunas del debate se deban a que todavía sólo se incluyen análisis parciales desde la óptica de la ciencia política y de las relaciones entre economía y política. Es decir, está aún ausente el análisis en los términos que tradicionalmente han interesado a la sociología. Para desarrollarlo creemos que deben explorarse las relaciones entre el proceso de articulación de intereses y desarrollo de las organizaciones, las formas y contenidos de las relaciones interorganizativas (pactos, negociaciones, competencia) y los cambios sociales que están produciendo. El análisis corporatista debería integrar, en este sentido, el estudio de las organizaciones en los siguientes niveles:

- Intensidad del desarrollo organizativo: Número de organizaciones y miembros que forman parte de ellas; grado de concentración o monopolización de las actividades por una o varias organizaciones; distribución geográfica. En una palabra, densidad corporativa.

- Caracteristicas de las organizaciones: Normas para la admisión de miembros; representatividad y democracia internas; proceso y órganos de toma de decisiones; formalización, división interna del trabajo y diferenciación estructural; criterios de acceso a las recompensas económicas y de status; mecanismos para mantener la coordinación imperativa; empleo de elementos simbólicos en el mantenimiento de la cohesión interna; régimen jurídico de fundación y funcionamiento; status público adquirido; ámbitos en los que se reconoce su participación de jure o de facto.

- Relaciones interorganizativas: Agrupaciones y federaciones de organizaciones con criterio sectorial y espacial; régimen jurídico de la creación y mantenimiento de las agrupaciones y federaciones; redes de dependencia entre organizaciones; procesos de toma de decisiones y acuerdos interorganizativos; grado de coordinación imperativa que se puede practicar en las agrupaciones. Y Last but not least, conflictos generales específicamente por las relaciones intercorporativas. Deberían, además, analizarse y sistematizarse los tipos de contactos y negociaciones, según objetivos y número de grupos que intervienen, entre las organizaciones públicas y privadas y entre éstas entre sí.

A través del conocimiento de estos aspectos pueden establecerse indicadores del grado de corporatización real y de sus efectos en una sociedad o en una parte de ella. Es muy probable que estos datos demuestren que las tendencias corporatistas son muy desiguales entre unos y otros ámbitos de 
actividad $\mathrm{y}$, sobre todo, que el grado de coordinación final es una cuestión problemática e impredecible en función de la variabilidad de la estructura organizativa que ha de conducir a ella.

El desarrollo organizativo, especialmente en el ámbito de la articulación de intereses, se ha visto estimulado por las dificultades que la democracia liberal encuentra en la actualidad para canalizar adecuadamente un conjunto cada vez más complejo y disperso de intereses a través de los mecanismos de la representación parlamentaria, de los partidos políticos y de los sindicatos. Estas instituciones tradicionales pueden verse desbordadas para asumir las demandas sectoriales, locales, de minorías, que en ocasiones son incluso contradictorias. Por eso surgen organizaciones de ámbito local, regional o nacional para la defensa de intereses de todo tipo: urbanísticos, ecológicos, culturales, que no se vinculan directamente a partidos políticos, sindicatos o patronales. No obstante, estas instituciones tradicionales de la democracia liberal tratan de influir sobre aquellas otras, bien para desarrollar sus programas o para cooptar el voto y lograr el necesario apoyo político. Se produce así una red de contactos y vinculaciones entre las instituciones representativas del sistema parlamentario y las que proliferan en la sociedad civil, que mediatizan el sistema organizativo a que nos referíamos antes.

El análisis corporatista debería, por tanto, basarse en un estudio previo del sistema de representación de intereses en una sociedad determinada y sus vinculaciones con los mecanismos clásicos de representación en la democracia liberal. Sin un conocimiento preciso de tales procesos es difícil concluir sobre uno de los temas presentes en el debate actual: el desplazamiento que el corporatismo significa de la forma tradicional de desarrollar la politica a través del parlamento y del sistema de partidos. Sin duda, una de las cuestiones más importantes en el debate corporatista son las relaciones entre estas tendencias y el funcionamiento de las instituciones democráticas. Hasta ahora los avances sobre esta cuestión son escasos ${ }^{78}$. Para analizarla deberían considerarse las siguientes esferas:

- Las vinculaciones institucionales y personales entre miembros del gobierno y la administración, partidos políticos, grupos parlamentarios, sindicatos, organizaciones empresariales, así como asociaciones de todo tipo que persiguen influir en la orientación de la política estatal.

- Las características del proceso de negociación que tiene lugar en los ámbitos de la concertación y de cualquier otro tipo entre los representantes del gobierno, la administración y las organizaciones privadas: dónde se toma la iniciativa, cómo se establecen los marcos de referencia para los acuerdos, cómo obligan los acuerdos a las partes, con qué grado de autonomía participan las partes en la negociación.

${ }^{73}$ G. Lehmbruch (1983) insiste en la necesidad de tener en cuenta estas relaciones, que constituyen una condición para el desarrollo del corporatismo. 
El papel que el Estado desempeña en las sociedades capitalistas avanzadas también ha propiciado la creación de organizaciones, ya que la existencia de éstas es condición favorable para que las decisiones políticas puedan llevarse a la práctica no sólo por mandato legal, sino también mediante la aceptación voluntaria por parte de los grupos afectados. En este sentido, el análisis corporatista debería dirigir su atención hacia los mecanismos de toma de decisión en el Estado y hacia la participación que tienen en ellos las diversas organizaciones involucradas. En concreto, deberían ser objeto de estudio los siguientes aspectos: criterios empleados por la administración pública para establecer consultas y negociaciones con organizaciones privadas; vías de acceso de las organizaciones privadas a la administración pública para influir en la toma de decisiones; estrategias de las organizaciones privadas para acceder e influir en las decisiones de la administración; estrategias de la administración para obtener el apoyo de organizaciones privadas en la aplicación de sus decisiones políticas. A partir de aquí podrían construirse modelos más acordes con la realidad de la práctica corporatista ${ }^{79}$.

$\mathrm{El}$ análisis no debe reducirse sólo a los aspectos anteriores, sino que también debe prestarse atención a los efectos sociales de la corporatización. Desde el punto de vista del conflicto social, en las sociedades corporativas se ha producido una ruptura de la concepción clásica del conflicto de clases como forma de conflicto hegemónico. Puede decirse que la conflictividad social por la distribución de recursos en las sociedades desarrolladas está en gran medida corporatizada, planteándose las luchas con carácter general y a través de organizaciones sectoriales y, en casos extremos, de ámbito exclusivamente intraempresarial. Estas luchas se plantean con reivindicaciones diferentes de un sector a otro y se resuelven con acuerdos también distintos, produciéndose, por tanto, una diferenciación interna en la situación de la clase trabajadora. Asimismo, la proliferación de organizaciones de representación de intereses ha significado un incremento del número de conflictos sectoriales. En este sentido, el análisis de las tendencias corporatistas debería incluir el estudio de las características de la conflictividad social desde la perspectiva de la mediatización que se produce en ella a través de las organizaciones.

En cuanto a los modos de estructuración social, las tendencias corporatistas han tenido efectos importantes. Así, la jerarquización interna de las organizaciones ha hecho más compleja la diferenciación interna de las organizaciones y ha hecho más compleja también la diferenciación interna de las clases sociales; los líderes y dirigentes forman una élite social interconectada entre sí, a modo de nueva aristocracia; las organizaciones han inducido en sus miembros formas de integración e identificación que se han convertido en subculturas. En cierta medida, las organizaciones proporcionan a sus miembros grupos de pertenencia y referencia que han sustituido en parte a los constituidos por clanes y familias. Por otra parte, desde el punto de vista indivi-

${ }^{79}$ Nos remitimos a las críticas hechas a la definición de Schmitter. 
dual, las organizaciones son determinantes tanto de la identidad de sus miembros como de sus conflictos personales. $\mathrm{El}$ conocimiento de estos aspectos nos daría una visión mucho más ajustada del significado sociológico del corporatismo.

Nuestra intención, al hacer todos estos comentarios, ha sido resaltar lo poco que conocemos sobre los efectos sociales de la corporatización y plantear, por ello, que el debate debe enmarcarse en sus justas dimensiones, si es que ha de ser fructífero. Lo anterior pretende, en cierta medida, establecerlas.

\section{BIBLIOGRAFIA}

Albrow, M.: Bureaucracy, Londres, Pall Mall, 1970.

AlemanN, U. von, y Heinze, R. G. (eds.): Verbande und Staat, Opladen, Westdeutscher Verlag, 1979.

Alemann, U. von (ed.): Neokorporatismus, Francfort, Campus Verlag, 1981.

AllardT, E.: «Representative Government in a Bureaucratic Age», en Daedalus, vol. 113, núm. 1, pp. 169-197, 1984.

ANDERSON, C.: «Political Design and the Representation of Interests», en Comparative Political Studies, vol. 10, núm. 1, pp. 127-152, 1977.

BeLL, D.: The comming of Post-Industrial Society, Londres, Heinemann (trad. cast. en Alianza Ed.), 1974.

BEYME, K. vON: «Der liberale Korporatismus als Mittel gegen die Unregierbarkeit?», en AlemanN, U., 1981.

BlAU, P., y SCotT, R.: Formal organizations, Londres, Routledge and Keagan, 1963.

Boulding, K.: The Organizational Revolution, Chicago, 1953.

BOWER, R. H.: German Theories of the Corporative State, Nueva York, Russell and Russell, 1974.

Casado, D., y Pérez Yruela, M.: Organización, conflicto y estrategias de negociación, Madrid, Marova, 1975.

Cawson, A.: «Pluralism, Corporatism and the Role of the State», en Government and Opossition, vol. 13, núm. 2, pp. 178-198, 1978.

Cawson, A. (ed.): Organized Interests and the State: Studies in Meso-Corporatism, Londres, Sage, 1985.

Crouch, C.: «The State, Capital and Liberal Democracy», en Crouch, C. (ed.): State and Economy in Contemporary Capitalism, Londres, Croom Helm, pp. 13.55, 1979.

Crouch, C., y Pizzorno, A.: The Resurgence of Class Conflict in Western Europe, Londres, MacMillan, 1978.

Collins, R.: Conflict Sociology, Nueva York, Academic Press, 1975.

DAINTIT H, T.: Imperium and Dominium: Constitutional Features of Group Bargaining and Policy Implementation, Florencia, European University Institute, 83 Summer School on Comparative European Politics, 1983.

DAR HENDORF, R.: Class and Class Conflict in an Industrial Society, Londres, Routledge and Keagan (trad. cast., Ed. Rialp), 1959.

Elbow, M. H.: French Corporative Theory, Nueva York, Octagon Books, 1966.

García Pelayo, M.: «El Estado Social y sus implicaciones», en García Pelayo, M. (1977 a): Las transformaciones del Estado contemporáneo, Madrid, Alianza Ed., pp. 1382, 1977.

García Pelayo, M.: «Sociedad Organizacional y Sistema Político», en García PelaYo, M. (1977), pp. 92-107, 1977 b.

García Pelayo, M.: «Nota sobre la idea del Estado en la Socialdemocracia clásica», en García Pelayo, M. (1977), pp. 83-91, 1977 c.

García Pelayo, M.: «Las organizaciones de intereses y la teoría constitucional», en García Pelayo, M. (1977), pp. 108-134, $1977 d$. 
GINER, S.: «Las sociogénesis de la desigualdad y la estructura de las sociedades corporativas», en Papers, núm. 20, 1981.

Giner, S.: «Centre and Periphery and Ethnic Nationalism in Spain», en ABel, C., y Torrents, N. (eds.): Spain, Conditional Democracy, Londres, Croom Helm, 1983.

Giner, S., y Pérez Yruela, M.: La Sociedad Corporativa, Madrid, Centro de Investigaciones Sociológicas, 1979.

Giner, S., y Pérez Yruela, M.: «¿Sin señas de identidad?», en El País, Madrid, 7 de abril de 1985 .

GoldT H ORPE, J. H.: The End of Convergence, Florencia, European University Institute, 83 Summer School in Comparative European Politics, 1983.

Jessop, B.: «Corporatism, Parliamentarism and Social Democracy», en Sch MITTER, P., y Lembruc H, G. (eds.) (1979): Trend Towards Corporatist Intermediation, Londres, Sage, pp. 155-212, 1979.

Kumar, K.: Propbecy and Progress: The Sociology of Industrial and Post-Industrial Society, Hardmondsworth, Penguin, 1978.

Le m m BRUCH, G.: «Consociational Democracy and the New Corporatism», en SCHMiTTER, P., y Lembruch, G. (eds.) (1979): Trends Towards Corporatist Intermediation, Londres, Sage, pp. 53-61, 1979 a.

- «Liberal Corporatism and Party Government», en Sc H MITTER, P., y Le H MBRUCH, G. (eds.) (1979): Trends Towards Corporatist Intermediation, pp. 147-183, 1979 b (publicado primero en 1977, en Comparative Political Studies, vol. 10, núm. 1, pp. 91-126).

- The Logic and Structural Conditions of Neocorporatist Concertation, Florencia, European University Institute, 83 Summer School on Comparative Politics, 1983.

Mallet, S.: La Nouvelle Classe Ouvrière, París, Editions du Seuil, 1963.

Malloy, J. M. (ed.): Autoritarianism and Corporatism in Latin America, Pittsburgh University Press, 1977.

Mann, M.: Consciousness and Action among the Western Working Class, Londres, MacMillan, 1978.

Maraffi, M. (ed.): La Società Neo-Corporativa. Introduzione, Bolonia, Il Mulino, 1981.

Miller, A. S.: The Modern Corporate State, Westport Conn., Grediwood Press, 1976.

Moyano Estrada, E.: Corporatismo y Agricultura, Madrid, Servicio de Publicaciones Agrarias, 1984.

Nedelman, B., y Meier, K. G.: «Theories of Contemporary Corporatism: Static or Dynamic?", en SCH MITTER, P., y Le H mBRUCH, G. (eds.) (1979): Trends Towards Corporatist Intermediation, Londres, Sage, pp. 95-118, 1979.

OfFE, C.: «The Attribution of Public Status to Interests Groups: Observations on the West German», en BERGER, S. (ed.) (1981): Organizing Interests in Western Europe, Cambridge Univ. Press, pp. 123-158, 1981.

Orson, M.: The logic of Collective Action, Cambridge Mass., Harvard Univ. Press, 1965.

Panitc H, L.: «The Development of Corporatism in Liberal Democracies», en Sc H MITTER, P., y LE H MBRUCH, G. (eds.) (1979): Trends Towards Corporatist Intermediation, Londres, Sage, pp. 119-146, 1979.

- «Recent Theorizations of Corporatism: Reflections on a Growth Industry», en British Journal of Sociology, vol. 31, núm. 2, pp. 159-187, 1980.

- «rade Unions and The Capitalist Statew, en New Left Review, eneromarzo, pp. 2143, 1981 .

Pappalardo, A.: Corporativism, Party Governement e Crisi Economica, Florencia, European University Institute, 83 Summer School in Comparative European Politics, 1983.

- «Politiche dei Reditti e Sindicati. Il limite dell'approccio organizativo», en Rivista Italiana di Scienza Politica, año XIV, núm. 3, pp. 433-477, 1984 (traducido en este número).

Pérez Díaz, V.: «Gobernabilidad y mesogobiernos: autonomías regionales y neocorporatismo en España», Papeles de Economía Española, núm. 21, pp. 40-76, 1985.

Pike, F. P., y Strich, T. (eds.): The New Corporatism: Socio Political Structures in the Iberian World, Notre Dame, University of Notre Dame Press, 1974.

Pizzorno, A.: «Interests and Parties in Pluralism», en Berger, S. (ed.): Organizing Interests in Western Europe, Cambridge Univ. Press, pp. 247-284, 1981.

Prest hus, R.: The Organizational Society, Londres, MacMillan, 1979. 
Regrni, M.: Types of Political Exchange in Western Europe: Different Conditions and Outputs of Concertation, Florencia, European University Institute, 83 Summer School on Comparative European Politics, 1983.

Robinson, J.: The Economics of Imperfect Competition, Londres, MacMillan, 1933.

Roca, J.: Teories Macroeconomiques $i$ Neo-Corporativisme, Florencia, European University Institute, 83 Summer School on Comparative European Politics, 1983.

SCHMITTER, P.: «Still the century of Corporatism?», en SCHMITTER, P., y LEHMBRUC H, G. (eds.) (1979): Trends Towards Corporatist Intermediation, Londres, Sage, pp. 7.52, 1979 (publicado en 1974 en The Review of Politics, vol. 36, núm. 1).

- «Interest Intermediation and Regime Governability in Contemporary Western Europe and North Americam, en BERGER, S. (ed.) (1981): Organizing Interests in Western Europe, Cambridge Univ. Press, pp. 285-327, 1981.

- «Reflections on where the theory of Corporatism has gone and where the Praxis of Neocorporatism May Be Going», en Lem mbruch, G., y Sch MitTer, P. (eds.): Patterns of Corporatist Policy Making, Londres, Sage, 1982.

- Neocorporatism, Consensus, Governability and Democracy in the Management of Crisis in Contemporary Advanced Industrial Societies, Florencia, European University Institute, 83 Summer School on Comparative European Politics, 1983.

- Neocorporatism and the State, Florencia, European University Institute, 1984 a.

- Democratic Theory and Neocorporatist Practice, Florencia y Chicago, mimeo, próxima publicación, $1984 b$.

Silverman, D.: The Theory of Organizations, Londres, Heinemann, 1971.

SolÉ, C.: "El debate corporativismo-neocorporativismo», en Revista Española de Inves. tigaciones Sociológicas, Madrid, núm. 26, pp. 9.27, 1984.

Stepan, A.: The State and Society: Peru in comparative perspective, Princeton University Press, 1978.

Strezck, W., y Sch mitter, P.: Community, Market, State -and Associations? The Prospective Contribution of Interests Governance to Social Order, Florencia, European University Institute, 1983.

Tomlinson, J.: "Corporatism: A Further Sociologisation of Marxism", en Power and Politics, núm. 4, pp. 237-237, 1984 (traducido en este número).

Villain, J.: La enseñanza social de la Iglesia, Madrid, Aguilar, 1957.

Walton y McKenzIE: A Bebabioural Theory of Labor Negotiations, Nueva York, McGraw Hill, 1965.

WestergaARD, J.: "Class, Inequality and Corporatism", en Hunt, A. (ed.): Class and Class Structure, Londres, Lawrence and Wishart, pp. 165-186, 1978.

WINKLER, J.: «Corporatism», en Arch. Europ. Sociol., XVII, pp. 100-136, 1976. 